\title{
Diagnostics of Collisions between Electrons and Water Molecules in Near-ultraviolet and Visible Wavelengths
}

\author{
D. Bodewits ${ }^{1}$ (i), J. Országh ${ }^{2}$ (1), J. Noonan ${ }^{3}$ (1) , M. Ďurian² ${ }^{2}$ and Š. Matejč́́k ${ }^{2}$ (10 \\ ${ }^{1}$ Physics Department, Leach Science Center, Auburn University, Auburn, AL 36832, USA; dennis@auburn.edu \\ ${ }^{2}$ Department of Experimental Physics, Faculty of Mathematics, Physics and Informatics, Comenius University in Bratislava, Mlynská dolina F-2, 84248 Bratislava; \\ Slovak Republic; juraj.orszagh@uniba.sk, matejcik@fmph.uniba.sk \\ ${ }^{3}$ Lunar and Planetary Laboratory, University of Arizona, 1629 E University Boulevard, Tucson, AZ 85721-0092, USA \\ Received 2019 July 17; revised 2019 September 6; accepted 2019 September 9; published 2019 November 12
}

\begin{abstract}
We studied the dissociation reactions of electron impact on water vapor for several fragment species at optical and near-ultraviolet wavelengths $(200-850 \mathrm{~nm})$. The resulting spectrum is dominated by the hydrogen Balmer series, by the $\mathrm{OH}\left(\mathrm{A}^{2} \Sigma^{+}-\mathrm{X}^{2} \Pi\right)$ band, and by the emission of ionic $\mathrm{H}_{2} \mathrm{O}^{+}\left(\mathrm{A}^{2} \mathrm{~A}_{1}-\mathrm{X}^{2} \mathrm{~B}_{1}\right)$ and $\mathrm{OH}^{+}\left(\mathrm{A}^{3} \Pi-\mathrm{X}^{3} \Sigma^{-}\right)$ band systems. Emission cross sections and reaction channel thresholds were determined for energies between 5 and $100 \mathrm{eV}$. We find that the electron impact dissociation of $\mathrm{H}_{2} \mathrm{O}$ results in an emission spectrum of the $\mathrm{OH}\left(\mathrm{A}^{2} \Sigma^{+}-\mathrm{X}^{2} \Pi\right)$ band that is distinctly different from the emission spectra from other excitation mechanisms seen in planetary astronomy. We attribute the change to a strongly non-thermal population of rotational states seen in planetary astronomy. This difference can be utilized for remote probing of the contribution of different physical reactions in astrophysical environments.
\end{abstract}

Unified Astronomy Thesaurus concepts: Laboratory astrophysics (2004); Molecular spectroscopy (2095); Small solar system bodies (1469); Atomic spectroscopy (2099); Electron impact ionization (2059); Excitation rates

(2067); Molecule destruction (2075); Collision processes (2065)

\section{Introduction}

Dissociative electron impact excitation reactions can provide a remote diagnostic of neutral gases and the physical environment of atmospheres around planets and small bodies in our solar system (Galand \& Chakrabarti 2002). It provides distinct spectral fingerprints in the infrared, optical, and ultraviolet wavelengths, and its efficiency is strongly dependent on both the electrons' energy and on the target molecule (Itikawa \& Mason 2005). As such, electron dissociative excitation and subsequent emission have been used to identify water plumes emanating from Europa (Hall et al. 1995; Roth et al. 2014), to remotely identify a tenuous $\mathrm{O}_{2}$ atmosphere around Callisto (Cunningham et al. 2015), and recently, by the Rosetta orbiter to study neutral gases in the inner coma of 67P/Churyumov-Gerasimenko (Feldman et al. 2015, 2018; Bodewits et al. 2016) and its interaction with a coronal mass ejection (Noonan et al. 2018).

Both the Europa and 67P/Churyumov-Gerasimenko results have sparked new interest in electron impact reactions with molecules abundant in the atmospheres of small bodies (including $\mathrm{H}_{2} \mathrm{O}, \mathrm{CO}_{2}, \mathrm{CO}, \mathrm{HCN}, \mathrm{O}_{2}, \ldots$ ) at energies between 0 and $100 \mathrm{eV}$. They also highlighted gaps and limitations in existing data sets (Van de Burgt et al. 1989; Avakyan et al. 1998; Itikawa \& Mason 2005; McConkey et al. 2008). Cross sections for several excitation-emission features are often measured only at one or two electron energies; many times only relative cross sections are available, or cross sections vary greatly between different groups.

There are large differences between measurements caused by the different methods used (for example crossed-beam versus gas cell experiments), overlapping emission features that make it difficult to measure the entire emission cross section of a given excited product, ambiguities in data processing (correction for lifetimes), the effects of energy resolution, the calibration of the electron sources used, and even the temperature of the target gas. For example, Table 6 in Van de Burgt et al. (1989) shows a factor of four difference across measurements of the $\mathrm{HI}$, O I $121.7 \mathrm{~nm}$ optical excitation function for electrons colliding with $\mathrm{H}_{2} \mathrm{O}$, even after renormalization. A similar issue can also be seen with O I $130.4 \mathrm{~nm}$ in both Van de Burgt et al. (1989) and Makarov et al. (2004). To make full use of the diagnostic qualities of electron impact emission, reliable measurements of the energy dependence of emission features in both visible and ultraviolet wavelengths are needed, at near-threshold electron energies.

Here, we report on laboratory measurements of electron impact reactions with water vapor at energies relevant for the atmospheres of small bodies such as comets (Broiles et al. 2016) and Europa (75\% of electrons below $205 \mathrm{eV}$; Bagenal et al. 2015). We first briefly describe the experimental apparatus and our data reduction (Section 2), then we discuss the measured cross sections and reaction channel thresholds (Section 3). We conclude this manuscript with a discussion of the diagnostic application to small body (cometary) atmospheres (Section 4).

\section{Experiment and Analysis \\ 2.1. Electron Fluorescence Apparatus}

The experiments were carried out using a crossed-beam apparatus using distilled and deionized water. The apparatus has been described in detail in previous publications (Danko et al. 2016; Országh et al. 2017) and is briefly described here. The electron beam generated by an electron gun crosses perpendicularly with a molecular beam formed by an effusive capillary in the vacuum chamber. In the experiments discussed in this manuscript we used the trochoidal electron monochromator (TEM) only for a small number of measurements due to the low intensity of produced electron beam and low 
values of the emission cross sections of the reactions leading to weak photon signal. The entire chamber was heated to approximately $60^{\circ} \mathrm{C}$ to prevent condensation of $\mathrm{H}_{2} \mathrm{O}$ vapor. We ensured that gas pressures did not exceed the single collision regime-an electron hits only one molecule. The energy resolution of the electron beam produced with the TEM was $600 \mathrm{meV}$ full width half maximum (FWHM) with electron currents typically between 0.3 and $2 \mu \mathrm{A}$. The electron gun had an electron energy distribution with a FWHM of $3 \mathrm{eV}$ and currents between 5 and $8 \mu \mathrm{A}$. For both sources, the electron energy range considered was $5-100 \mathrm{eV}$. The gas pressure, ambient pressure, and electron current were all electronically monitored and logged.

Photons produced by the reactions were guided out of the vacuum chamber by a system of mirrors and lenses and focused onto the entrance slit of the Czerny-Turner optical monochromator (resolution $\lambda / d \lambda=972$ at $100 \mathrm{~mm}$ slit width). To acquire a broad-range overview spectrum we used a Hamamatsu R3896 photomultiplier tube sensitive between 185 and $900 \mathrm{~nm}$. To acquire more detailed spectra, we used a Hamamatsu R4220P photomultiplier tube, which is more sensitive and has lower noise in the UV range than the R3896 photomultiplier. We determined the spectral response function of the optical system in the visible and near-infrared by measuring blackbody radiation emitted by a heated tungsten filament of known temperature. We determined the spectral sensitivity response in the ultraviolet range by measuring the continuum emission of $\mathrm{H}_{2}\left(\mathrm{a}^{3} \Sigma_{\mathrm{g}}^{+}-\mathrm{b}^{3} \Sigma_{\mathrm{u}}^{+}\right)$at $14 \mathrm{eV}$. The shape of the hydrogen continuum spectrum published by James et al. (1998) and the theoretical blackbody spectrum were used as a reference each in its corresponding spectral range. The final spectral response function was determined as a ratio of measured spectra and reference spectra. The instrumental field of view is given by the optical monochromator acceptance angle and the parameters and positions of the used lenses and mirror. The interaction region from which the emitted photons can reach the photomultiplier is approximately $3 \mathrm{~mm}$ in diameter for a $100 \mu \mathrm{m}$ slit width.

Two complementary methods were applied to measure electron-collision-energy-dependent emission spectra: wavelength scans at a fixed electron energy, and electron-energy scans at a fixed wavelength corresponding to specific emission features of interest. In both cases, typical exposure times were $10 \mathrm{~s}$ per measurement step. Profiles of the emission intensity with respect to electron incident energy were derived by averaging over at least three scans.

\subsection{Calibration Procedures}

To ensure good signal-to-noise for the optical monochromator we used relatively large background gas pressures in the reaction chamber $\left(\sim 10^{-4}\right.$ mbar). At the pressures used for our experiments polar water molecules form a deposit on the electrodes of the electron gun (Berman 1996), which causes a linear offset in the electron energy. To correct for this. the energy of the electron beam was first absolutely calibrated by introducing a mixture of $\mathrm{N}_{2}$, helium, and $\mathrm{H}_{2} \mathrm{O}$ into the setup and by measuring the intensity profile of the $\mathrm{N}_{2}\left(\mathrm{C}^{3} \Pi_{\mathrm{u}}\right.$ and $\left.\mathrm{B}^{3} \Pi_{\mathrm{g}}\right)(0-0)$ band at $337 \mathrm{~nm}$ and the He I $\left(1 \mathrm{~s} 2 \mathrm{p}{ }^{3} P_{1,2}^{0}-1 \mathrm{~s} 4 \mathrm{~d}\right.$ ${ }^{3} D_{1,2,3^{-}}$) emission line at $447.14 \mathrm{~nm}$. The former has a sharp maximum at an electron energy of $14.1 \mathrm{eV}$ (Országh et al. 2012), and the latter has a threshold at an electron energy of $23.736 \mathrm{eV}$ (NIST 2015). We then measured the energy dependence of the intensity of the $\mathrm{H}_{\beta}$ emission for both the gas mixture and the pure $\mathrm{H}_{2} \mathrm{O}$ beam. By fitting the $\mathrm{H}_{2} \mathrm{O}$-only $\mathrm{H}_{\beta}$ profile to the $\mathrm{H}_{\beta}$ profile of the $\mathrm{H}_{2} \mathrm{O} / \mathrm{N}_{2} / \mathrm{He}$ mixture, we corrected for the linear offset of the electron energy in our $\mathrm{H}_{2} \mathrm{O}$ experiments.

The energy dependence of the emission lines intensities was determined by positioning the optical monochromator at the peak of the lines, and then scanning over the electron-energy range. The absolute calibration of the excitation curve was achieved by scaling the curve of the $\mathrm{H}_{\beta}$ line at $100 \mathrm{eV}$ to the measurements by Müller et al. (1993), $4.9 \times 10^{-19} \mathrm{~cm}^{2}$. Then the intensity of the spectrum was scaled such that the area below the spectral line corresponded to the value of the crosssection curve at $50 \mathrm{eV}$. In this procedure we assume that only the relative cross section and not the shape of the atomic line changes with electron energy. Other emission lines were calibrated by scaling the data according to $\mathrm{H}_{\beta}$.

To determine the emission cross section of the much broader molecular emission features, the area under the band was integrated after the spectral intensity was calibrated according to $\mathrm{H}_{\beta}$. Specific emission cross-section normalization details are discussed later in the paper.

\subsection{Thresholds}

Several steps are visible in the relation between emission cross sections and the electron energy. These steps or onsets indicate the thresholds for opening of new reaction channels for given dissociative excitation processes. We determined the position of these threshold energies by fitting a theoretical threshold function consisting of a constant background and a linear function. The intersection of the two functions determines the threshold. More sophisticated routines are available, but they require data with higher signal-to-noise ratios. The noise in the measured signal affects the uncertainty of the determined value more significantly than the uncertainty introduced by the fitting method.

\subsection{Uncertainties}

The measured emission cross sections are subject to several uncertainties. The largest contribution to the uncertainty in the cross sections originates from the spectral intensity calibration process in which we anchor our data to the dissociative emission cross section of the $\mathrm{H}_{\beta}$ line produced by electron impact on water vapor by Müller et al. (1993), who claimed a systematic uncertainty of only $10 \%$ (see Section 2.2). As discussed in Section 1, results reported by other groups vary widely. This uncertainty affects all data points and leads to a simple scaling factor.

The uncertainty of the sensitivity of the spectrometer is between $20 \%$ for the shortest (200-250 nm) and longest $(750-850 \mathrm{~nm})$ wavelengths and is approximately $5 \%$ for the middle section $(250-750 \mathrm{~nm})$ of the region.

The data were not corrected for electron beam and target pressure variations, which both introduce a random error of approximately $5 \%$. Both the pressure and electron current were logged and measurements where either of these varied by more than $10 \%$ were discarded. Every scan over electron energy was repeated at least 5 times and the standard deviation in signal counts was used to determine that the stochastical errors in every energy bin were on the order of $5 \%$. 


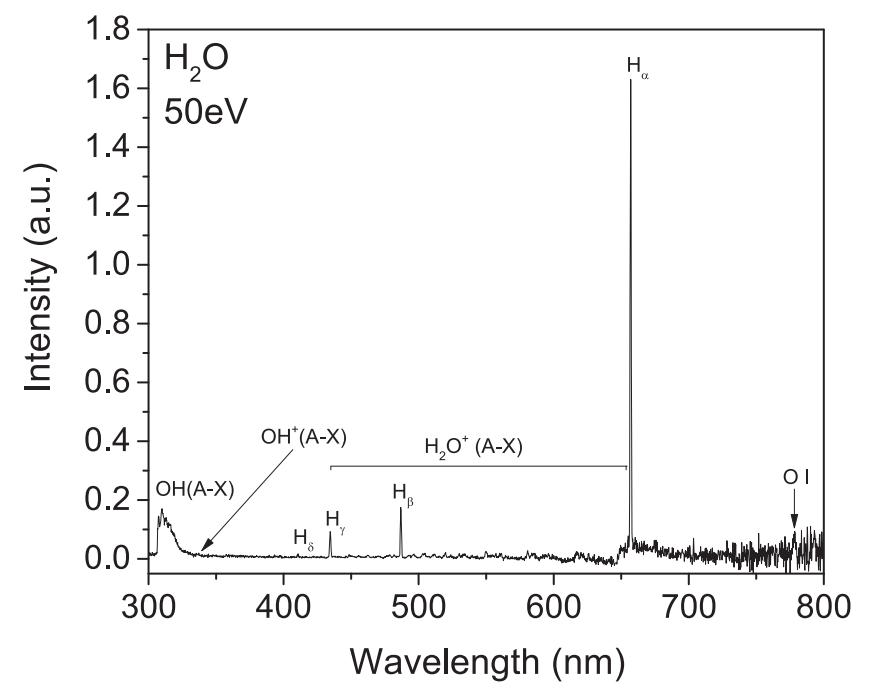

Figure 1. Overview of the emission spectrum and the main features induced by electron impact on water vapor at an incident energy of $50 \mathrm{eV}$. The intensity values are corrected for instrument sensitivity.

No method for determination of polarization of the emitted light was used in this experiment, introducing an error of less than $5 \%$.

The long lifetime of the higher $n \geqslant 5$ states of the hydrogen atom results in a large fraction of the Balmer emission series not being detected (Section 2.2). We corrected our measurements for this by assuming a velocity of $7 \mathrm{~km} \mathrm{~s}^{-1}$; in reality the fragments' velocity distributions also have faster components that are added with increasing collision energy (Kouchi et al. 1979; Kurawaki et al. 1983; Makarov et al. 2004). Consequently, the cross sections of the $\mathrm{H}_{\gamma, \delta, \varepsilon}$ may be underestimated somewhat at higher collision energies.

Finally, the uncertainty of the electron-energy calibration is mostly driven by the energy distribution of the electron beam that has an FWHM of $0.6 \mathrm{eV}$, equivalent to a $1 \sigma$ error of $0.26 \mathrm{eV}$.

\section{Results and Discussion}

We measured the electron-induced emission spectrum of water at an incident electron energy of $50 \mathrm{eV}$ in the spectral region from 200 to $800 \mathrm{~nm}$. An overview spectrum $(300-800 \mathrm{~nm})$ is presented in Figure 1. It was acquired at a lower spectral resolution of $1 \mathrm{~nm}$ with wider optical monochromator slits of $300 \mu \mathrm{m}$. The main features of the spectrum are the $\mathrm{OH}\left(\mathrm{A}^{2} \Sigma^{+}-\mathrm{X}^{2} \Pi\right)$ bands and the hydrogen Balmer lines produced by the dissociative electron impact of water molecules. In addition, weaker bands produced by electron dissociation and ionization processes were detected, namely $\mathrm{OH}^{+}\left(\mathrm{A}^{3} \mathrm{\Pi}-\mathrm{X}^{3} \Sigma^{-}\right)$and $\mathrm{H}_{2} \mathrm{O}^{+}\left(\mathrm{A}^{2} \mathrm{~A}_{1}-\mathrm{X}^{2} \mathrm{~B}_{1}\right)$. Finally, we marginally detected an emission line from atomic oxygen at $777 \mathrm{~nm}$ (where our detector has lower sensitivity, corresponding to the O I $\left(3 s^{5} S^{0}-3 p^{5} \mathrm{P}\right)$ transition. The [O I] emission lines from the forbidden transitions at 557.7, 630.0, and $636.4 \mathrm{~nm}$ are not detected in our experiment, owing to the long lifetimes of the metastable $\left(2 \mathrm{P}^{4}\right)^{1} \mathrm{~S}$ and $\left(2 \mathrm{P}^{4}\right)^{1} \mathrm{D}$ states (see Bhardwaj \& Raghuram 2012).

\subsection{Hydrogen Balmer Series}

In our spectra we can reliably detect the Balmer series up to $\mathrm{H}_{\varepsilon}$. The higher-order transitions of the Balmer series have a
Table 1

Lifetimes of the Excited States (Wiese \& Fuhr 2009), the Distance a Hydrogen Atom Travels in That Time Assuming an Energy of $0.26 \mathrm{eV}\left(7 \mathrm{~km} \mathrm{~s}^{-1}\right.$; Makarov et al. 2004), and the Fraction of the Population That Decays within the Field of View for Each Emission Line in the Balmer Series

\begin{tabular}{lcccr}
\hline \hline Transition & Name & $\begin{array}{c}\text { Lifetime } \\
(\mathrm{ns})\end{array}$ & $\begin{array}{c}\text { Distance } \\
(\mathrm{mm})\end{array}$ & $\begin{array}{c}\text { Decayed } \\
(\%)\end{array}$ \\
\hline $3-2$ & $\mathrm{H}_{\alpha}$ & 22.73 & 0.16 & 100 \\
$4-2$ & $\mathrm{H}_{\beta}$ & 119.1 & 0.83 & 83 \\
$5-2$ & $\mathrm{H}_{\gamma}$ & 395.3 & 2.77 & 42 \\
$6-2$ & $\mathrm{H}_{\delta}$ & 1028 & 7.19 & 19 \\
$7-2$ & $\mathrm{H}_{\varepsilon}$ & 2273 & 15.91 & 9 \\
\hline
\end{tabular}

relative long lifetime (Table 1) allowing a significant fraction of the hydrogen atoms to leave the field of view (diameter $3 \mathrm{~mm}$ ) before emitting a photon. Doppler profile measurements (not possible with our spectral resolution) and translational energy spectroscopy measurements indicate that the hydrogen atoms have significant velocities throughout the range of $6-8 \mathrm{~km} \mathrm{~s}^{-1}$ $(0.19-0.34 \mathrm{eV})$, and that their velocity distribution changes when additional reaction channels open (Kouchi et al. 1979; Kurawaki et al. 1983; Makarov et al. 2004). This implies that all the $\mathrm{H}_{\alpha}$ decays within our field of view, but that as much as $91 \%$ of the $\mathrm{H}_{\varepsilon}$ emission is not detected. In published studies, it is often unclear what correction is applied, if any at all.

The spectral region between 430 and $750 \mathrm{~nm}$ contains many $\mathrm{H}_{2} \mathrm{O}^{+}$subbands (Section 3.4). The possible overlap with the $\mathrm{H}_{2} \mathrm{O}^{+}$emission can affect the Balmer series cross-section determination. However, because of the low intensity of the $\mathrm{H}_{2} \mathrm{O}^{+}$bands and because the much brighter hydrogen lines are very narrow, the impact of the $\mathrm{H}_{2} \mathrm{O}^{+}$background on the Balmer series is negligible.

Emission cross sections and thresholds of the Balmer series are shown in Figures 2 and 3 and in Table 2. All show a steep increase starting around $18 \mathrm{eV}$, with the threshold increasing from 17.7 to $19.5 \mathrm{eV}$ going from $\mathrm{H}_{\alpha}$ to $\mathrm{H}_{\delta}$. The signal-to-noise ratio for the $\mathrm{H}_{\varepsilon}$ line was too low to reliably determine a first activation threshold. The thresholds are consistent with those reported in previous studies (Table 3 ) and are all about $0.5 \mathrm{eV}$ higher than the thermochemical minimum thresholds for the reaction $\mathrm{H}_{2} \mathrm{O}+\mathrm{e} \rightarrow \mathrm{OH}\left(\mathrm{X}^{2} \Pi^{+}\right)+\mathrm{H}(n p)$ (Table 4). All Balmer emission cross sections show a second onset between 23.6 and $25.5 \mathrm{eV}$. This energy range is consistent with several reactions that result in complete dissociation of the water molecule and with the production of excited hydrogen and excited neutral or ionized hydroxyl. The emission cross-section profiles of the $\mathrm{OH}\left(\mathrm{A}^{2} \Sigma^{+}-\mathrm{X}^{2} \Pi^{+}\right)($Section 3.2$)$ and $\mathrm{OH}^{+}(\mathrm{A}$ $\left.{ }^{2} \Sigma^{+}-\mathrm{X}^{2} \Pi^{+}\right)$bands have thresholds around 9.4 and $13 \mathrm{eV}$, consistent with the production of hydrogen in the ground state. They also show small kinks at 20 and $23 \mathrm{eV}$, above the thresholds for the production of excited hydrogen occurs according to the thermochemical estimates.

Our cross-section values for the Balmer series of hydrogen are in agreement with those published by Müller et al. (1993) within experimental uncertainty. The values reported by Beenakker et al. (1974) and Möhlmann \& De Heer (1979) are in general higher and finally the values reported by Vroom \& De Heer (1969) are significantly higher. Our experiment is based on the crossed-beams method. Müller et al. (1993) utilizes both the crossed-beams and collision-cell methods and in the remaining three publications the collision cell filled with gas to a specific pressure was used. The cross-section values in 
Table 2

Emission Cross Sections $\sigma$ (in Units of $10^{-20} \mathrm{~cm}^{2}$ ) for Hydrogen Balmer Series at Electron Impact Energies of 50 and $100 \mathrm{eV}$ for Our Measurements and Previously Reported Values

\begin{tabular}{|c|c|c|c|c|c|c|c|c|c|c|}
\hline $\begin{array}{l}\text { Emission cross section } \\
\text { Energy }(\mathrm{eV})\end{array}$ & $\begin{array}{l}\mathrm{H}_{\alpha} \\
50\end{array}$ & $\begin{array}{l}\mathrm{H}_{\alpha} \\
100\end{array}$ & $\begin{array}{l}\mathrm{H}_{\beta} \\
50\end{array}$ & $\begin{array}{c}\mathrm{H}_{\beta} \\
100\end{array}$ & $\begin{array}{l}\mathrm{H}_{\gamma} \\
50\end{array}$ & $\begin{array}{c}\mathrm{H}_{\gamma} \\
100\end{array}$ & $\begin{array}{l}\mathrm{H}_{\delta} \\
50\end{array}$ & $\begin{array}{c}\mathrm{H}_{\delta} \\
100\end{array}$ & $\begin{array}{l}\mathrm{H}_{\varepsilon} \\
50\end{array}$ & $\begin{array}{c}\mathrm{H}_{\varepsilon} \\
100\end{array}$ \\
\hline This work & 133 & 265 & 31.2 & 49 & 17 & 25 & 6.6 & 10.5 & 5 & 6.7 \\
\hline Möhlmann \& De Heer (1979) & 224 & 355 & $\cdots$ & 68.3 & $\cdots$ & 27.3 & $\cdots$ & 10.2 & $\cdots$ & 4.16 \\
\hline Beenakker et al. (1974) & $\cdots$ & $\cdots$ & 40.4 & 64.1 & $\cdots$ & $\cdots$ & $\cdots$ & $\cdots$ & $\cdots$ & $\cdots$ \\
\hline
\end{tabular}

collision-cell experiments are calculated based on the measured intensity and concentration of particles in the cell. In the case of Vroom \& De Heer (1969), the concentration determination was based on measurement of the sample cylinder temperature, which could negatively influence the uncertainty of crosssection evaluation, hence the discrepancy between the crosssection values published by Vroom \& De Heer (1969) and later papers. The long lifetime of higher excited states contributing to Balmer series (given in Table 1) significantly affects the photon signal intensity in crossed-beam experiments, as a considerable part of the photons can be lost due to the limited field of view of the experimental device (see Table 1). After application of calculated correction factors, our values are comparable to Müller et al. (1993) and have similar trends as cross sections determined in collision-cell experiments, which supports the correctness of the used correction.

As is shown in Figure 3(A), all the curves of the emission cross sections of Balmer series show similar trends with respect to the collision energy. That agrees with Beenakker et al. (1974), who similarity reported values within $4 \%$ and deduced the other Balmer series cross sections from the $\mathrm{H}$ (4-2) value. In our experiment every emission cross section of $\mathrm{H}(n \rightarrow 2)$ has been determined individually from the experimental data and the determined cross sections are in good agreement with Beenakker's values. The similar shapes of the curves can also be seen from Figure 3(B) where the ratios of $\mathrm{H}_{\beta} / \mathrm{H}_{\alpha}$ and $\mathrm{H}_{\gamma} / \mathrm{H}_{\alpha}$ are roughly constant after they reach a maximum at approximately $40 \mathrm{eV}$.

In general, the authors of the published data do not describe experimental details such as the temperature of water vapor reacting with electron beam that may contribute to discrepancies of the published cross section values.

\subsection{Emission from $\mathrm{OH}$}

The emission spectrum of the $\mathrm{OH}\left(\mathrm{A}{ }^{2} \Sigma^{+}-\mathrm{X}{ }^{2} \Pi\right)$ transitions from 260 to $335 \mathrm{~nm}$ is shown in Figure 4. This region was measured with a higher spectral resolution than that used for the overview spectrum in Figure 1 and the signal accumulation time was increased to gain a better signal-tonoise ratio. Most of the emission occurs between 305 and $335 \mathrm{~nm}$, which contains the (0-0), (1-1), (2-2), and (3-3) bands; the section between 280 and $295 \mathrm{~nm}$ contains the (1-0) and (2-1) bands; and the faintest part of the spectrum occurs between 260 and $270 \mathrm{~nm}$, which contains the (2-0) band. Emission from the much fainter ionic $\mathrm{OH}^{+}\left(\mathrm{A}^{3} \Pi-\mathrm{X}^{3} \Sigma^{-}\right)$ band overlaps partially with the neutral $\mathrm{OH}\left(\mathrm{A}^{2} \Sigma^{+}-\mathrm{X}^{2} \Pi\right)$ emission between 250 and $350 \mathrm{~nm}$ and is shown separately in Figure 4.
Our absolute calibration of the emission cross section of electron impact produced $\mathrm{OH}\left(\mathrm{A}^{2} \Sigma^{+}-\mathrm{X}^{2} \Pi\right)$ is done by anchoring the flux in a small bandpass $\Delta \lambda$ to the emission cross section of $\mathrm{H}_{\beta}$ and by weighting this flux to the entire emission band based on an empirical rovibrational model. The cross section of $\mathrm{H}_{\beta}$ in turn was calibrated by comparing our signal at electron impact energies of $100 \mathrm{eV}$ to the emission cross section reported by Müller et al. (1993) at the same energy.

As discussed in Section 2.1, we acquire our measurements by either fixing the electron energy and adjusting the spectrometer to acquire a spectrum over a range of wavelengths, or by fixing the spectrometer at specific wavelengths (283.5 and $307.3 \mathrm{~nm}$ in our case; Figure 5(a)) and scanning over electron impact energy. To determine the total emission cross section of the different $\mathrm{OH}$ bands from the fixedwavelength measurements we employed a technique inspired by Müller et al. (1993), who fitted different simulated rovibrational distributions to the experimental $\mathrm{OH}$ spectrum to deconvolute the emission spectrum. This distribution cannot be directly determined from the experimental data due to limited spectral resolution.

To construct synthetic spectra of the sections from 280 to $305 \mathrm{~nm}$ and from 305 to $335 \mathrm{~nm}$, we simulated the spectrum using the Lifbase 2.1 software (Luque \& Crosley 1999) by varying the vibrational and rotational populations for $v^{\prime}=0,1$, 2 (Figure 6). To match the experimental and simulated spectra it was necessary to slightly adjust the wavelength calibration of the experimental spectrum by $0.3 \mathrm{~nm}$, which is within the experimental resolution of the optical monochromator. The baseline correction of the experimental spectrum was set to $0.55 \%$, a Gaussian line shape was found to better fit the experimental spectrum, and the resolution of synthetic spectrum was set to $0.5 \mathrm{~nm}$. Because the Lifbase software allows only manual adjustment of the rotational level populations in the model, we have started our approximation by first setting the populations according to Müller et al. (1993). We adjusted the populations manually to achieve a minimal residual after subtracting the fitted spectra from the measurement.

In Figure 6 we show the best-fit synthetic spectrum with the contributions of the $v^{\prime}=0,1$, and 2 bands, compared to a spectrum measured at an incident energy of $50 \mathrm{eV}$. Müller et al. (1993) also considered the $\mathrm{OH}^{+}\left(\mathrm{A}^{3} \Pi-\mathrm{X}^{3} \Sigma^{-}\right)(2-0)$ feature in their fit. Because the contribution of this band to the total emission is marginal and does not affect the fit to our data, we excluded it from the spectral model. In Figure 6 we show the relative population of the rotational states for individual vibrational states of $\mathrm{OH}\left(\mathrm{A}^{2} \Sigma^{+}\right)$, in agreement with previous 

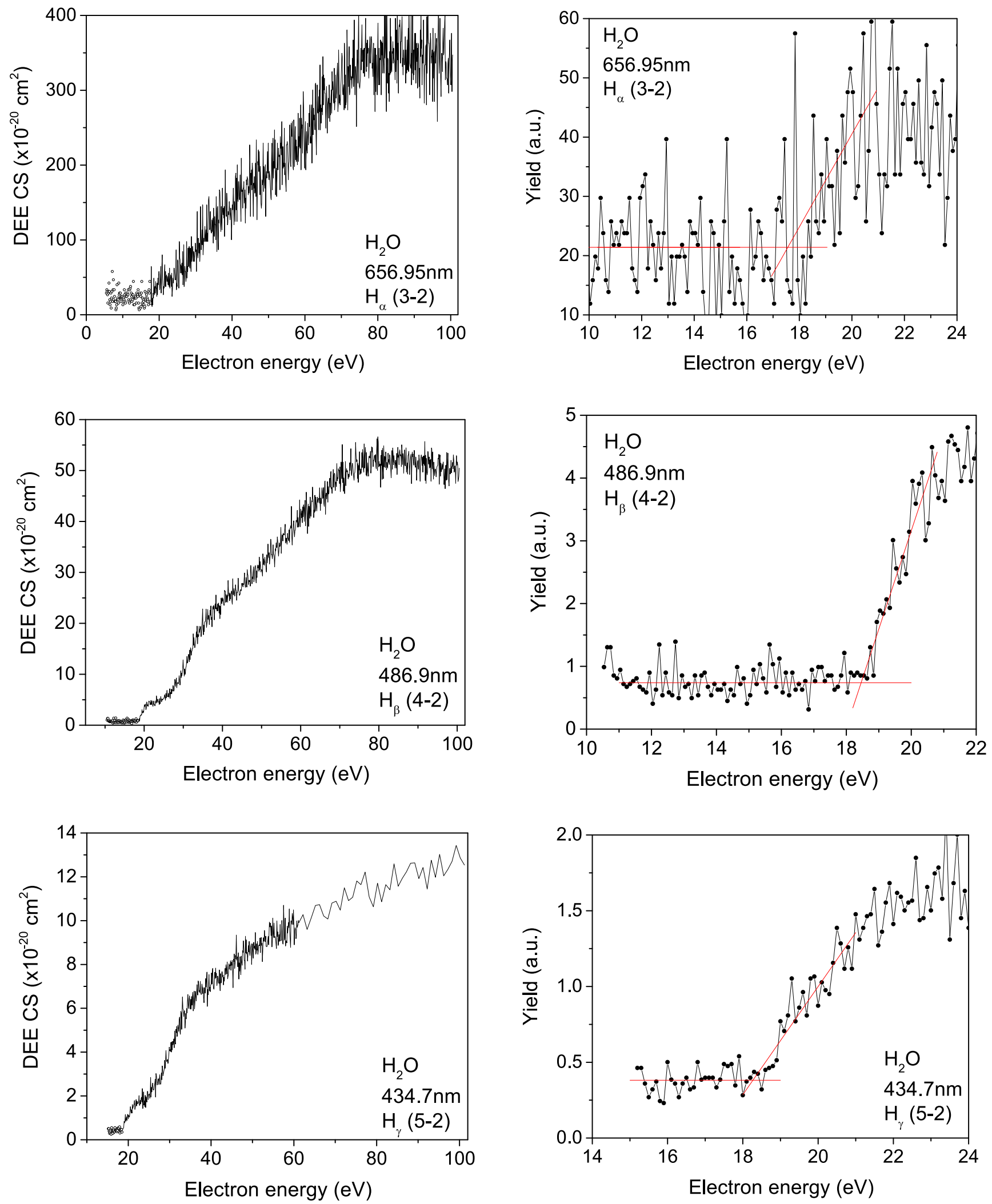

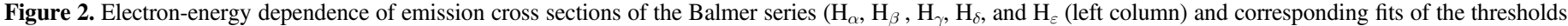
(right column). The signal-to-noise ratio of the $\mathrm{H}_{\varepsilon}$ emission line prevents fitting the thresholds.

studies (Müller et al. 1993; Möhlmann \& De Heer 1979). Based on the relative strengths of the $Q_{1}$ and $R_{1}$ bands the rotational temperature of the synthetic spectrum corresponds to approximately $2200 \mathrm{~K}$.
Next, we used the synthetic spectra to extrapolate total emission cross sections from the measurements at $283.6 \mathrm{~nm}$ and $307.3 \mathrm{~nm}$ by integrating the area under the curve for the specific band. For this we assumed that the relative distribution 

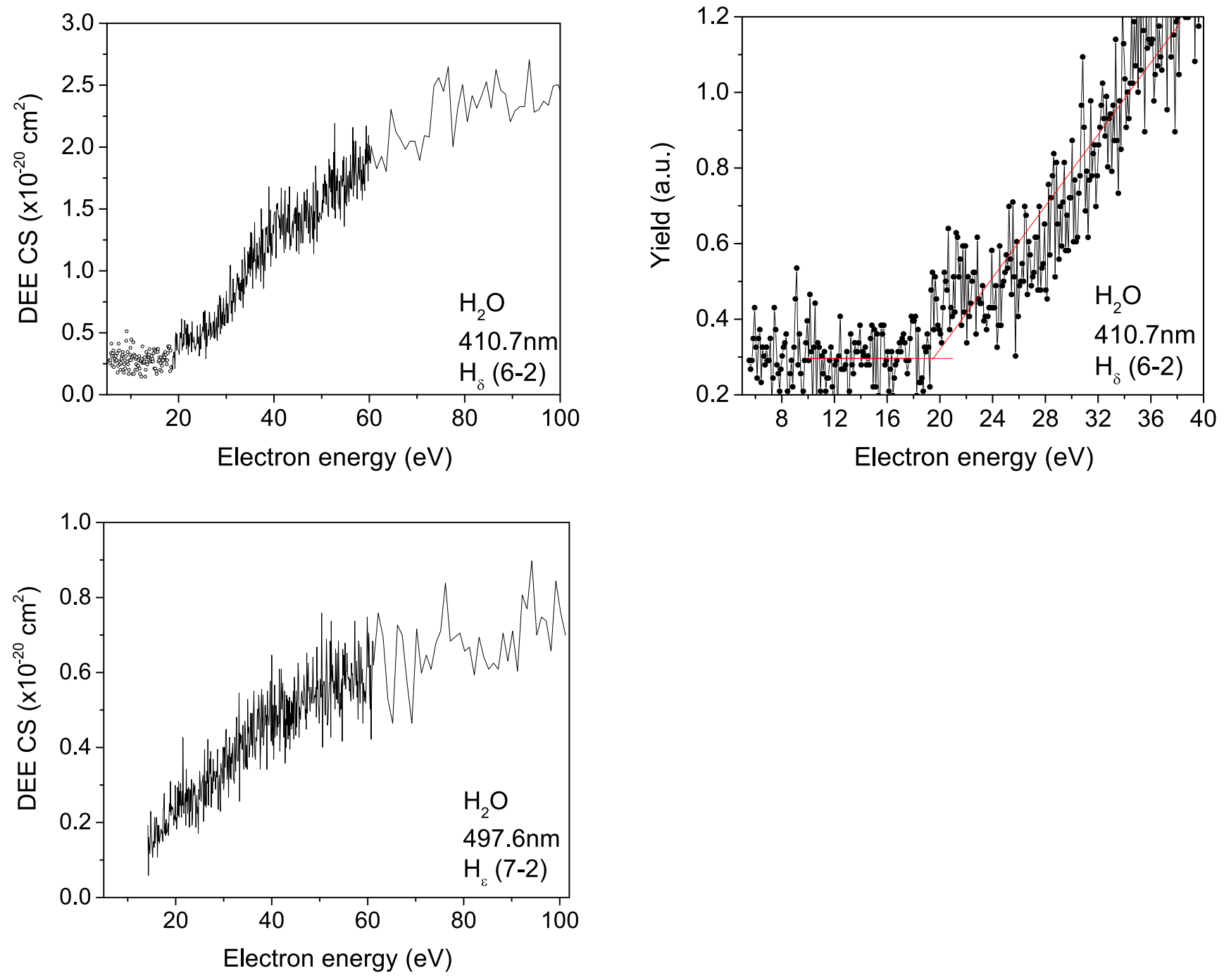

Figure 2. (Continued.)

of the rovibrational states was constant over the energy range considered here. We verified this assumption by comparing our distribution measured at $50 \mathrm{eV}$ by the vibrational distribution of Müller et al. (1993) that was measured at $100 \mathrm{eV}$. Our results are very similar, except for the population of rotational states for vibrational level $v^{\prime}=2$. We also looked at the ratio between the measured emission cross sections at 283.6 and $307.3 \mathrm{~nm}$ as a function of the incident electron energy. This ratio is approximately constant within $10 \%$, supporting the validity of our assumption.

The resulting emission cross sections for the different $\mathrm{OH}\left(\mathrm{A}^{2} \Sigma^{+}-\mathrm{X}^{2} \Pi\right)$ transitions at an impact energy of $50 \mathrm{eV}$ are summarized in Table 5. For comparison, we also give the values determined by Müller et al. (1993) acquired at an incident electron energy $100 \mathrm{eV}$. The first three rows in the Table $\left(v^{\prime}-v^{\prime \prime}=0-0,1-1,2-2\right)$ add to the emission between 307 and $330 \mathrm{~nm})$; the next two rows $\left(v^{\prime}-v^{\prime \prime}=1-0,2-1\right)$ constitute the emission between 280 and $295 \mathrm{~nm}$, and the last row $\left(v^{\prime}-v^{\prime \prime}=2-0\right)$ corresponds to a band between 260 and $270 \mathrm{~nm}$ (see Figure 6). As the three individual bands that constitute each of the two emission features cannot be distinguished in the measured spectra, we add the emission cross sections of these bands to derive the "unresolved emission cross section." The cross sections given by Müller et al. (1993) are approximately two times larger than our values for both unresolved band and resolved bands. That corresponds to the increase of the relative cross-section curve at $100 \mathrm{eV}$ in comparison to $50 \mathrm{eV}$ even though the increase is not that intensive.

The $\mathrm{OH}$ emission from water has previously been studied by several groups using different techniques. The reported emission cross sections for $\mathrm{OH}\left(\mathrm{A}^{2} \Sigma^{+}-\mathrm{X}^{2} \Pi\right)$ differ markedly. Müller et al. (1993) reported a value measured at an electron energy of $100 \mathrm{eV}$ that is approximately $30 \%$ lower than the value reported by Beenakker et al. (1974). However, it is necessary to note the difference between their experimental techniques. While Beenakker et al. (1974) used a cell filled with gas as a target, Müller et al. (1993) and Makarov et al. (2004) both used crossed-beam setups to determine the cross sections. All three experiments used simple electron guns to generate electron beams. Both Beenakker et al. (1974) and Makarov et al. (2004) measure velocity-dependent cross sections with a monochromator, thus requiring extrapolation from a fixed, small range in wavelength to the entire $\mathrm{OH}\left(\mathrm{A}^{2} \Sigma^{+}-\mathrm{X}^{2} \Pi\right)$ band to determine absolute emission cross sections (similar to our method). According to Becker et al. (1980) the polarization of the emission is $5.2 \% \pm$ $1.1 \%$ at $11.9 \mathrm{eV}$ and less than a few percent above $20 \mathrm{eV}$ and 

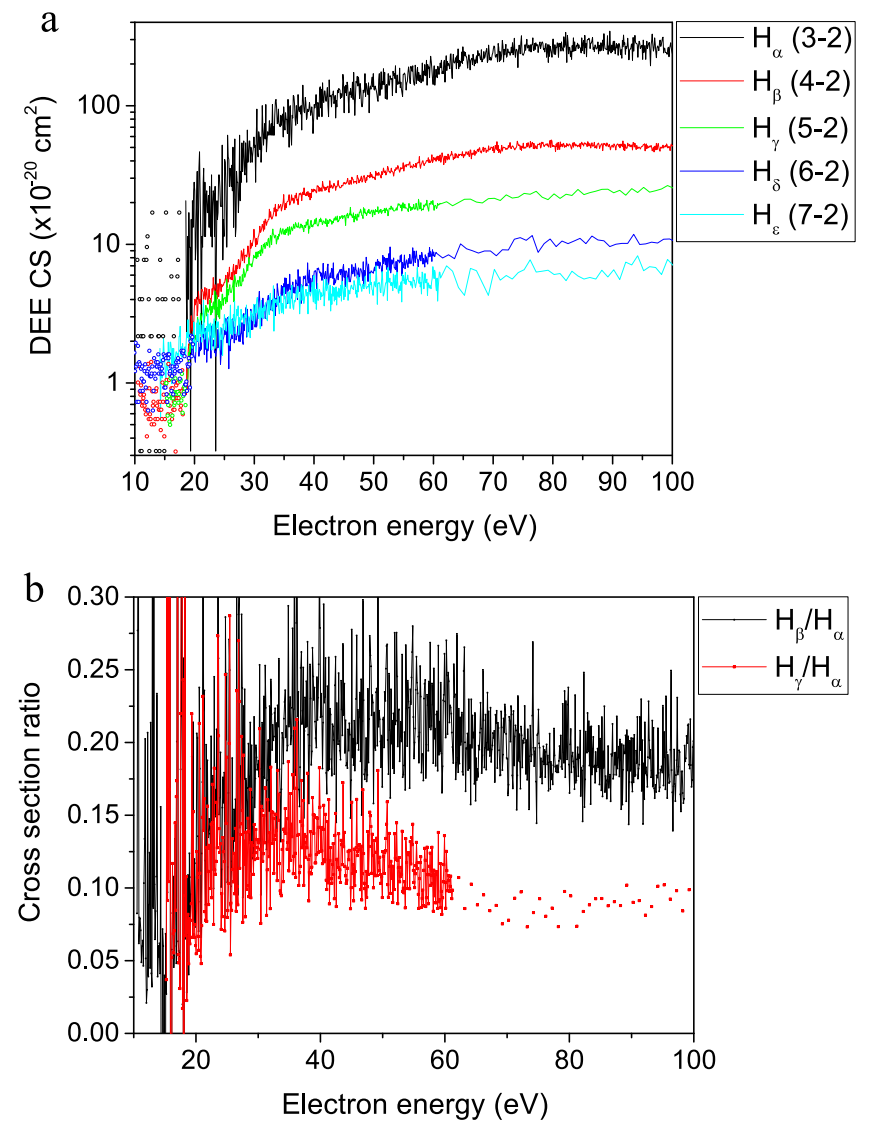

Figure 3. (a) Comparison of emission cross sections of the hydrogen Balmer series corrected for the loss of emission owing to the limited field of view. (b) Line ratios of the hydrogen Balmer series vs electron impact energy: $\mathrm{H} \beta / \mathrm{H} \alpha$-black line; $\mathrm{H} \gamma / \mathrm{H} \alpha$-red line.

Vroom \& De Heer (1969) detected no polarization above $50 \mathrm{eV}$. From all studies, Shappe \& Urban (2006) and Müller et al. (1993) were the only groups that separated various vibrational bands and determined corresponding $\mathrm{OH}\left(\mathrm{A}^{2} \Sigma^{+}-\mathrm{X}^{2} \Pi\right)$ cross sections.

For the reaction channel leading to $\mathrm{OH}\left(\mathrm{A}^{2} \Sigma^{+}-\mathrm{X}^{2} \Pi\right)$ emission we find a threshold of $9.4 \pm 0.3 \mathrm{eV}$, just above the thermochemical minimum energy $(9.24 \mathrm{eV})$ and in good agreement with previous measurements (Tables 3 and 4). The emission cross section peaks around $19.5 \mathrm{eV}$, then decreases until $65 \mathrm{eV}$. Our results indicate a slight increase again with increasing impact energy, which was not expected based on the measurements by Müller et al. (1993) and Beenakker et al. (1974). We attribute this different behavior on the heating of our setup. Khodorkovskii et al. (2009) investigated the effect of gas temperature on the electron impact-induced emission cross section of $\mathrm{OH}\left(\mathrm{A}^{2} \Sigma^{+}-\mathrm{X}^{2} \Pi\right)$. Their results agree with the first two papers at low nozzle temperatures $\left(16^{\circ} \mathrm{C}-24^{\circ} \mathrm{C}\right)$, and resemble ours at nozzle temperatures of $50^{\circ} \mathrm{C}$. The difference is explained by the dissociation of singlet states that are excited at these higher temperatures. Heating of our system to $60^{\circ} \mathrm{C}$ was necessary to avoid disruptive condensation of water vapor in the nozzle system.

\subsection{Emission from $\mathrm{OH}^{+}$}

For $\mathrm{OH}^{+}\left(\mathrm{A}^{3} \Pi-\mathrm{X}^{3} \Sigma^{-}\right)$we determined the cross section by integrating the surface area under the experimentally acquired spectrum (with calibrated intensity according to Section 2.2) between 333 and $378 \mathrm{~nm}$, rather than by developing a spectral model (see Table 6 for exact integration boundaries for individual cross sections). These values bear higher uncertainties than those of $\mathrm{OH}$, as the experimental spectrum contains noise and possibly a small contribution from the $\mathrm{OH}\left(\mathrm{A}^{2} \Sigma^{+}-\mathrm{X}^{2} \Pi\right)$. As is shown in Figure 4, the region of the $\mathrm{OH}^{+}\left(\mathrm{A}^{3} \Pi-\mathrm{X}^{3} \Sigma^{-}\right)$emission also contains two excited emission features and the wavelength bands containing these features were excluded from the cross-section integration. This adds to the uncertainty of our cross sections. The first feature is a strong, broad band between 342.9 and $346.5 \mathrm{~nm}$ that Müller et al. (1993) tentatively attributed to $\mathrm{OH}^{2+}$. Apart from $\mathrm{OH}^{+}$and $\mathrm{H}_{2} \mathrm{O}^{+}$(next section), mass spectroscopy experiments indicate that electron impact produces a multitude of fragment ions including $\mathrm{H}^{+}, \mathrm{H}_{2}^{+}, \mathrm{O}^{+}$, and $\mathrm{O}^{2+} ; \mathrm{OH}^{2+}$ does not appear to be a major dissociation product (King \& Price 2008), suggesting that the emission is produced by one of the other neutral or ionic fragments produced by the reaction. The second feature found around $377.9 \mathrm{~nm}$ might be attributed to excited $\mathrm{O}^{+}$ion, but if that were the case, we would expect multiple strong emission features between 400 and $480 \mathrm{~nm}$ due to the $\mathrm{O}^{+}(3 \mathrm{p}-3 \mathrm{~s})$ transitions, which were not observed.

The energy-dependent relative emission cross sections for $\mathrm{OH}^{+}\left(\mathrm{A}^{3} \Pi-\mathrm{X}^{3} \Sigma^{-}\right)$measured at $395.5 \mathrm{~nm}$ are shown in Figure 5(b). We determined a threshold around $23 \pm 0.3 \mathrm{eV}$. Using an $\mathrm{OH}$ ionization energy of $13.017 \mathrm{eV}$ (Ruscic et al. 2002) we find a thermochemical minimum appearance energy of $21.7 \mathrm{eV}$ for production of excited $\mathrm{OH}^{+}\left(\mathrm{A}^{3} \Pi\right)$. We found no other reported value for this threshold, but our results are in excellent agreement with studies of the photoionization threshold of $\mathrm{H}_{2} \mathrm{O}$ leading to the production of $\mathrm{OH}^{+}$in the ground state (Ruscic et al. 2002).

After a steep increase between 23 and $50 \mathrm{eV}$, the emission cross section of $\mathrm{OH}^{+}\left(\mathrm{A}^{3} \Pi-\mathrm{X}^{3} \Sigma^{-}\right)$reaches a plateau and then seems to decrease slightly with increasing energy up to $100 \mathrm{eV}$. Absolute emission cross sections are given in Table 5 and add up to a total of $6.4 \times 10^{-20} \mathrm{~cm}^{2}$, which is a factor of 25 less than the emission from neutral $\mathrm{OH}\left(\mathrm{A}^{2} \Sigma^{+}-\mathrm{X}^{2} \Pi\right)$. Our results are significantly lower than those reported by Müller et al. (1993), whose separate emission band cross sections add up to a total emission cross section of $29.8 \times 10^{-20} \mathrm{~cm}^{2}$.

\subsection{Emission from $\mathrm{H}_{2} \mathrm{O}^{+}$}

In the spectral region between 430 and $750 \mathrm{~nm}$ more than 400 subbands of $\mathrm{H}_{2} \mathrm{O}^{+}\left(\mathrm{A}^{2} \mathrm{~A}_{1}-\mathrm{X}^{2} \mathrm{~B}_{1}\right)$ transition can be found (Kuchenev \& Smirnov 1996). In Figure 7, a detail of part of this spectral region (between 430 and $560 \mathrm{~nm}$ ) is shown. The subbands were identified according to Kuchenev \& Smirnov (1996). To determine emission cross sections, a spectral resolution much higher than possible with our spectrometer is necessary, as the bands are spread over a large spectral range and overlap each other.

We measured the energy dependence of three relatively bright $\mathrm{H}_{2} \mathrm{O}^{+}$features that were reasonably separated from other spectral features with peaks at 496.3, 503, and $519.75 \mathrm{~nm}$ (Figure 8). These three features are all part of the $\mathrm{H}_{2} \mathrm{O}^{+}\left(\mathrm{A}^{2} \mathrm{~A}_{1}-\mathrm{X}^{2} \mathrm{~B}_{1}\right)$ band, corresponding to the transitions $(0,12,0)-(0,0,0)$ for the $p$ branch; $(0,13,0)-(0,1,0)$ for the $\mathrm{p}$ and $\mathrm{r}$ branches; and $(0,11,0)$ $(0,0,0)$ for the $\mathrm{p}$ branch, respectively. 
Table 3

Measured Thresholds $E_{\text {ap }}$ and Measured Values Previously Reported in the Literature

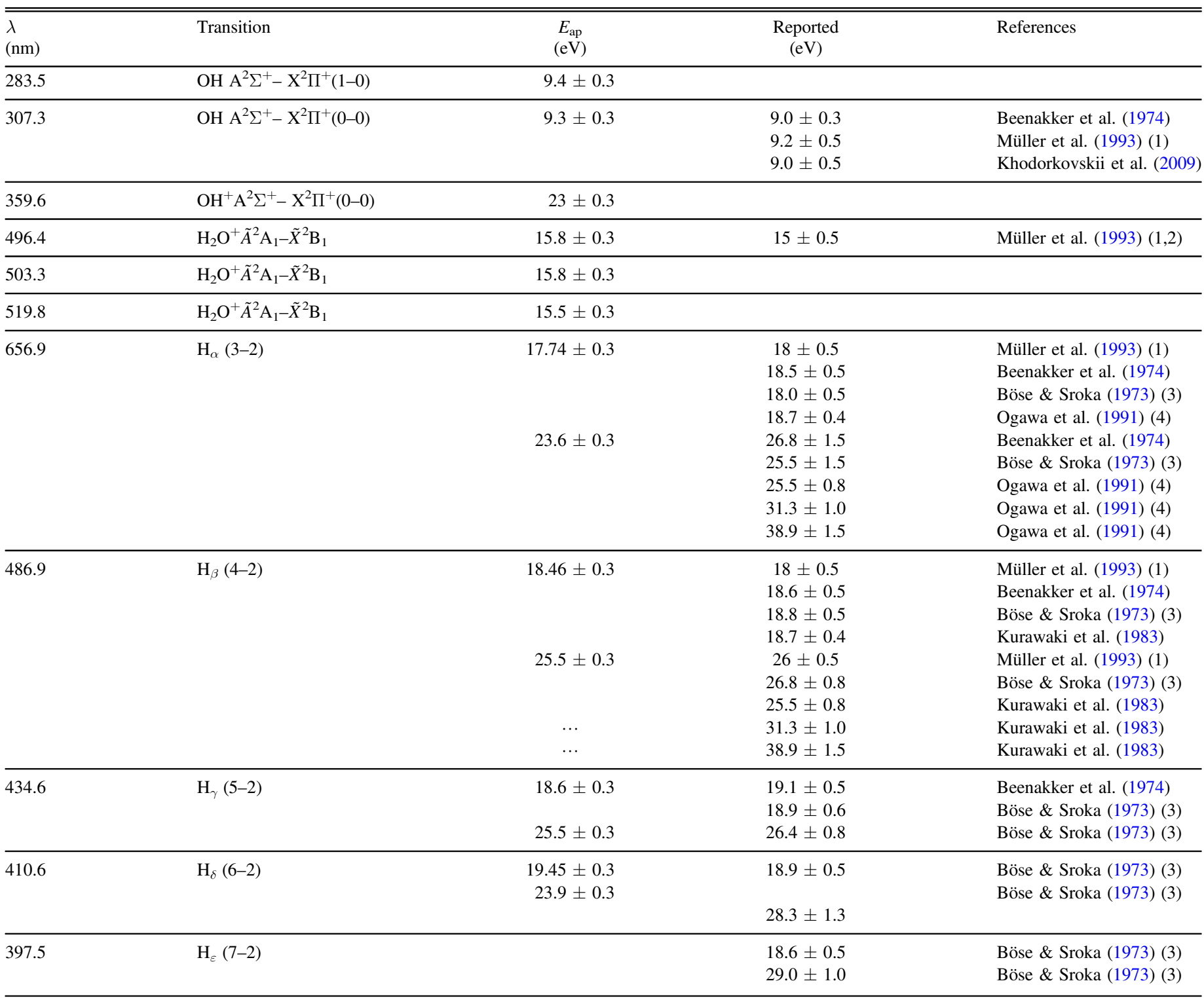

Note. (1) Uncertainty based on the half-width of the energy temp distribution. (2) Measured at $4614 \mathrm{~A}$ in the $(0,16,0 \rightarrow 0,2,0)$ band. (3) Based on the measured onset of the Lyman series. (4) Did not differentiate between $n=3$ and 4.

Table 4

Measured $\left(E_{\mathrm{ap}}\right)$ and Calculated Thermochemical $\left(E_{\min }\right)$ Minimal Appearance Energies of Emission Features at Wavelength $\lambda$

\begin{tabular}{|c|c|c|c|c|}
\hline $\begin{array}{l}\lambda \\
(\mathrm{nm})\end{array}$ & Transition & Products & $\begin{array}{l}E_{\min } \\
(\mathrm{eV})\end{array}$ & $\begin{array}{c}E_{\mathrm{ap}} \\
(\mathrm{eV})\end{array}$ \\
\hline $260-360$ & $\mathrm{OH}\left(\mathrm{A}^{2} \Sigma^{+}-\mathrm{X}^{2} \Pi^{+}\right)$ & $\begin{array}{l}\mathrm{OH}\left(\mathrm{A}^{2} \Sigma^{+}\right)+\mathrm{H} \\
\mathrm{OH}\left(\mathrm{A}^{2} \Sigma^{+}\right)+\mathrm{H}(2)\end{array}$ & $\begin{array}{r}9.24 \\
19.45\end{array}$ & $9.4 \pm 0.3$ \\
\hline $335-380$ & $\mathrm{OH}^{+}\left(\mathrm{A}^{2} \Sigma^{+}-\mathrm{X}^{2} \Pi^{+}\right)$ & $\begin{array}{l}\mathrm{OH}^{+}\left(\mathrm{A}^{2} \Sigma^{+}\right)+\mathrm{H} \\
\mathrm{OH}^{+}\left(\mathrm{A}^{2} \Sigma^{+}\right)+\mathrm{H}(2)\end{array}$ & $\begin{array}{l}21.66 \\
31.87\end{array}$ & $23 \pm 0.3$ \\
\hline $380-600$ & $\mathrm{H}_{2} \mathrm{O}^{+}\left(\tilde{A}^{2} \mathrm{~A}_{1}-\tilde{X}^{2} \mathrm{~B}^{1}\right)$ & $\mathrm{H}_{2} \mathrm{O}^{+}\left(\widetilde{\mathrm{A}}^{2} \mathrm{~A}_{1}\right)$ & 14.62 & $15.8 \pm 0.3$ \\
\hline 656.3 & $\mathrm{H}_{\alpha}(3-2)$ & $\begin{array}{l}\mathrm{OH}, \mathrm{H}(3) \\
\mathrm{OH}^{+}, \mathrm{H}(3) \\
\mathrm{OH}\left(\mathrm{A}^{2} \Sigma^{+}\right)+\mathrm{H}(3) \\
\mathrm{O}+\mathrm{H}+\mathrm{H}(3) \\
\mathrm{OH}^{+}\left(\mathrm{A}^{3} \Pi\right)+\mathrm{H}(3) \\
\left.\mathrm{O}^{1} \mathrm{~S}^{0}\right)+\mathrm{H}+\mathrm{H}(3)\end{array}$ & $\begin{array}{l}17.29 \\
20.80 \\
21.34 \\
21.74 \\
24.25 \\
25.94\end{array}$ & $17.74 \pm 0.3$ \\
\hline
\end{tabular}


Table 4

(Continued)

\begin{tabular}{|c|c|c|c|c|}
\hline $\begin{array}{l}\lambda \\
(\mathrm{nm})\end{array}$ & Transition & Products & $\begin{array}{l}E_{\min } \\
(\mathrm{eV})\end{array}$ & $\begin{array}{c}E_{\mathrm{ap}} \\
(\mathrm{eV})\end{array}$ \\
\hline 486.1 & $\mathrm{H}_{\beta}(4-2)$ & $\begin{array}{l}\mathrm{OH}, \mathrm{H}(4) \\
\mathrm{OH}+\mathrm{H}(4) \\
\mathrm{OH}\left(\mathrm{A}^{2} \Sigma^{+}\right)+\mathrm{H}(4) \\
\mathrm{O}+\mathrm{H}+\mathrm{H}(4) \\
\mathrm{OH}^{+}\left(\mathrm{A}^{3} \Pi\right)+\mathrm{H}(4) \\
\left.\mathrm{O}^{1} \mathrm{~S}^{0}\right)+\mathrm{H}+\mathrm{H}(4)\end{array}$ & $\begin{array}{l}17.94 \\
21.45 \\
21.99 \\
22.39 \\
24.90 \\
26.59\end{array}$ & $\begin{array}{r}18.46 \pm 0.3 \\
25.5 \pm 0.3\end{array}$ \\
\hline 434.0 & $\mathrm{H}_{\gamma}(5-2)$ & $\begin{array}{l}\mathrm{OH}, \mathrm{H}(5) \\
\mathrm{OH}+, \mathrm{H}(5) \\
\mathrm{OH}\left(\mathrm{A}^{2} \Sigma^{+}\right)+\mathrm{H}(5) \\
\mathrm{O}+\mathrm{H}+\mathrm{H}(5) \\
\mathrm{OH}^{+}\left(\mathrm{A}^{3} \Pi\right)+\mathrm{H}(5) \\
\mathrm{O}\left({ }^{1} \mathrm{~S}^{0}\right)+\mathrm{H}+\mathrm{H}(5)\end{array}$ & $\begin{array}{l}18.25 \\
21.76 \\
22.30 \\
22.70 \\
25.21 \\
26.90\end{array}$ & $\begin{array}{l}18.6 \pm 0.3 \\
21.6 \pm 0.3 \\
25.5\end{array}$ \\
\hline 410.2 & $\mathrm{H}_{\delta}(6-2)$ & $\begin{array}{l}\mathrm{OH}, \mathrm{H}(6) \\
\mathrm{OH}+\mathrm{H}(6) \\
\mathrm{OH}\left(\mathrm{A}^{2} \Sigma^{+}\right)+\mathrm{H}(6) \\
\mathrm{O}+\mathrm{H}+\mathrm{H}(6) \\
\mathrm{OH}^{+}\left(\mathrm{A}^{3} \Pi\right)+\mathrm{H}(6) \\
\left.\mathrm{O}^{1}{ }^{1} \mathrm{~S}^{0}\right)+\mathrm{H}+\mathrm{H}(6)\end{array}$ & $\begin{array}{l}18.41 \\
21.92 \\
22.46 \\
22.86 \\
25.37 \\
27.06\end{array}$ & $\begin{array}{r}19.45 \\
23.9\end{array}$ \\
\hline 397.0 & $\mathrm{H}_{\varepsilon}(7-2)$ & $\begin{array}{l}\mathrm{OH}, \mathrm{H}(7) \\
\mathrm{OH}^{+}, \mathrm{H}(7) \\
\mathrm{OH}\left(\mathrm{A}^{2} \Sigma^{+}\right)+\mathrm{H}(7) \\
\mathrm{O}+\mathrm{H}+\mathrm{H}(7) \\
\mathrm{OH}^{+}\left(\mathrm{A}^{3} \Pi\right)+\mathrm{H}(7) \\
\left.\mathrm{O}^{1} \mathrm{~S}^{0}\right)+\mathrm{H}+\mathrm{H}(7)\end{array}$ & $\begin{array}{l}18.51 \\
22.02 \\
22.56 \\
22.96 \\
25.47 \\
27.16\end{array}$ & \\
\hline
\end{tabular}
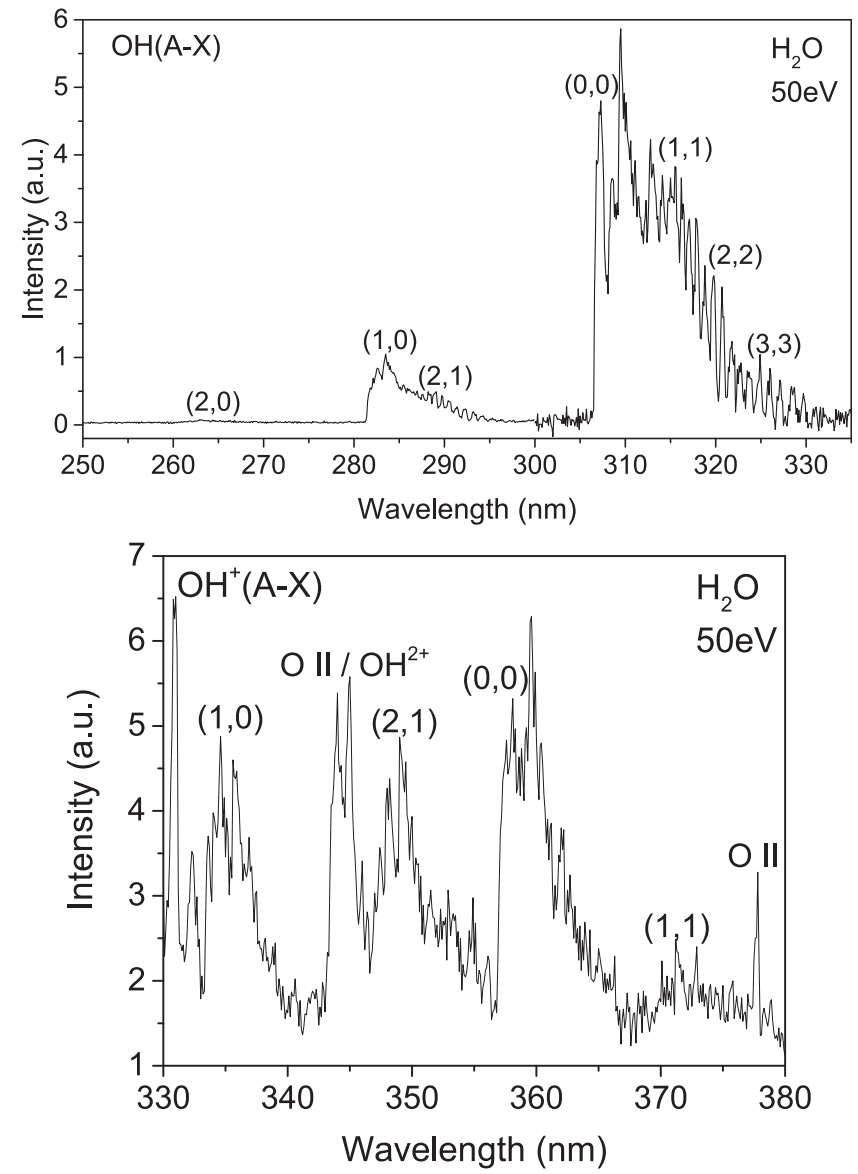

Figure 4. Details of $\mathrm{OH}\left(\mathrm{A}^{2} \Sigma^{+}-\mathrm{X}^{2} \Pi\right)$ (top) and $\mathrm{OH}^{+}\left(\mathrm{A}^{3} \Pi-\mathrm{X}^{3} \Sigma^{-}\right)$ (bottom) measured with high spectral resolution at an electron energy of $50 \mathrm{eV}$.
In Figure 8 the relative cross section curves for these three transitions are shown. The shapes of the curves are similar to each other and also to the curve reported by Müller et al. (1993) for the transition $(0,16,0)-(0,2,0)$. We find a threshold value of $15.8 \pm 0.3 \mathrm{eV}$, in agreement with the thermochemical minimum of $14.62 \mathrm{eV}$ and with the measured threshold value of $15.0 \pm 0.5 \mathrm{eV}$ reported by Müller et al. (1993).

In Table 6 the resulting cross sections at $50 \mathrm{eV}$ incident electron energy are shown including the integration boundaries used for their determination. The values are in reasonable agreement with Kuchenev \& Smirnov (1996), who show values approximately in the range of $1 \times 10^{-21} \mathrm{~cm}^{2}$ and $4 \times 10^{-20} \mathrm{~cm}^{2}$ for individual bands at $50 \mathrm{eV}$ electron impact energy. However, we note that due to the insufficient optical resolution of our experiment the values contain signal from several transitions. For comparison, Müller et al. (1993) only give a lower limit of the cross-section value for the spectral region $350-500 \mathrm{~nm}$ at $100 \mathrm{eV}$, which is $>1.25 \times 10^{-18} \mathrm{~cm}^{2}$.

\section{Examples of Diagnostic Applications in Comets}

Dissociative electron impact excitation provides a remote diagnostic of both the neutral gas and the electrons interacting with it (Section 1), and water vapor is ubiquitous in our solar system. Through spectral analysis and modeling that implements dissociative cross sections as a function of electron energy, the dominant emission source can be identified, and if spectral signal is high enough to capture a wide range of emission features with varying threshold energies it may even be possible to remotely determine plasma properties. However, to fully employ its diagnostic qualities, we need to distinguish between different mechanisms that excite fragment species 

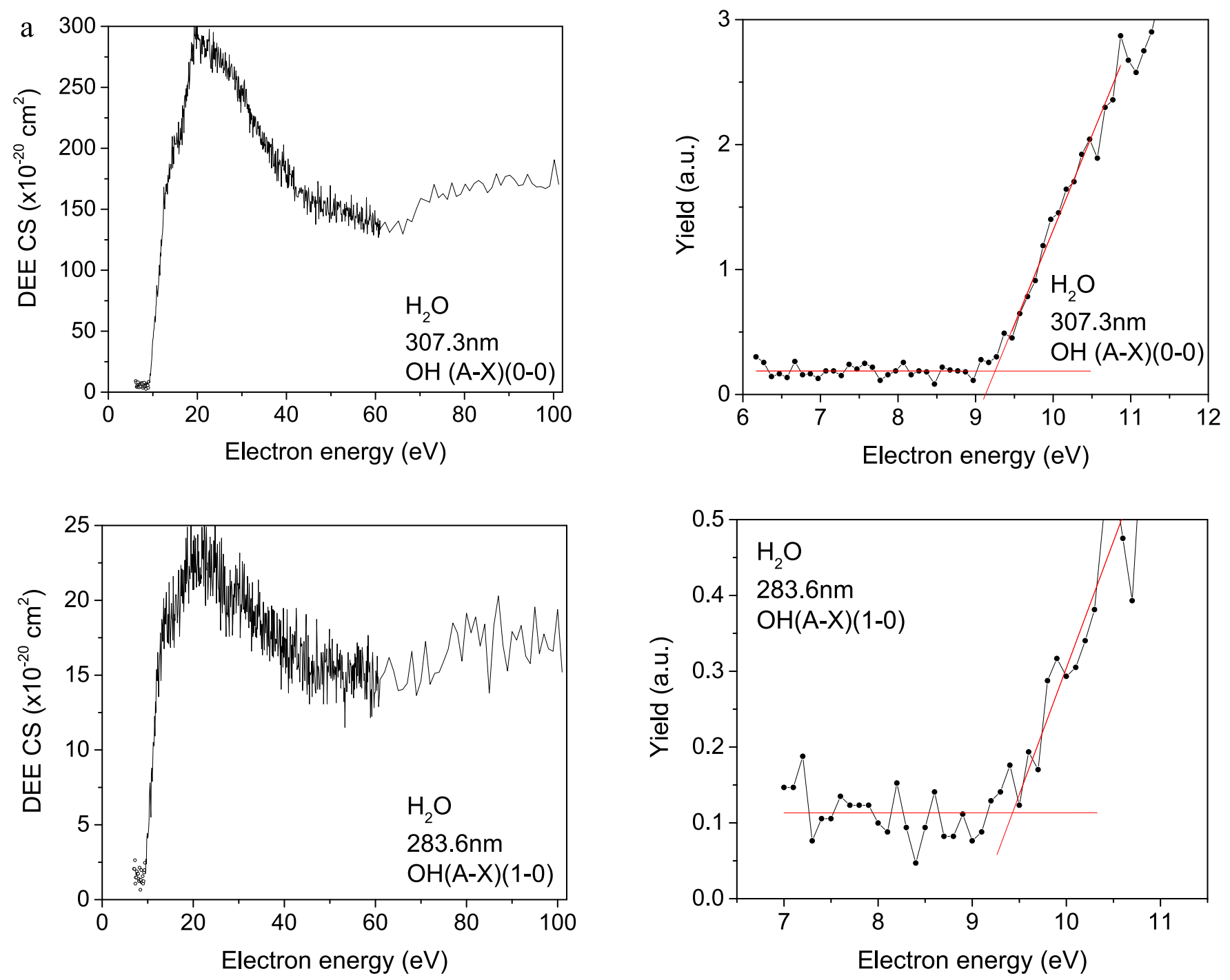

b
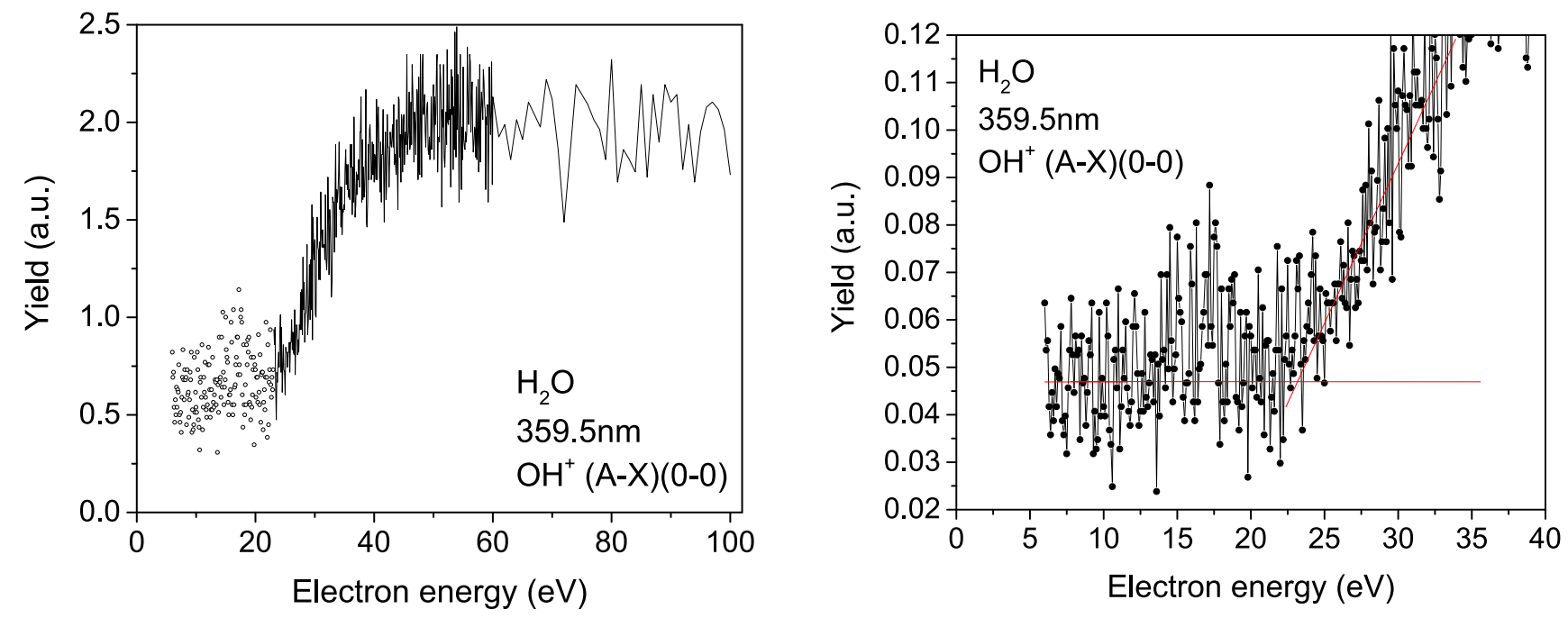

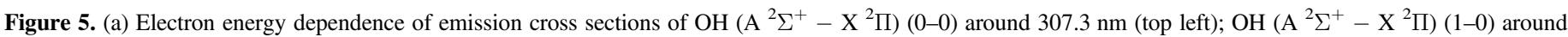

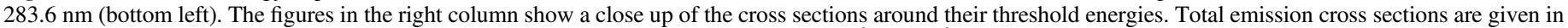

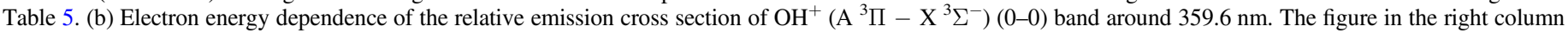

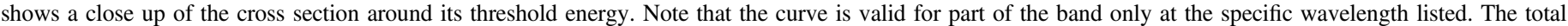
emission cross sections are given in Table 6. 

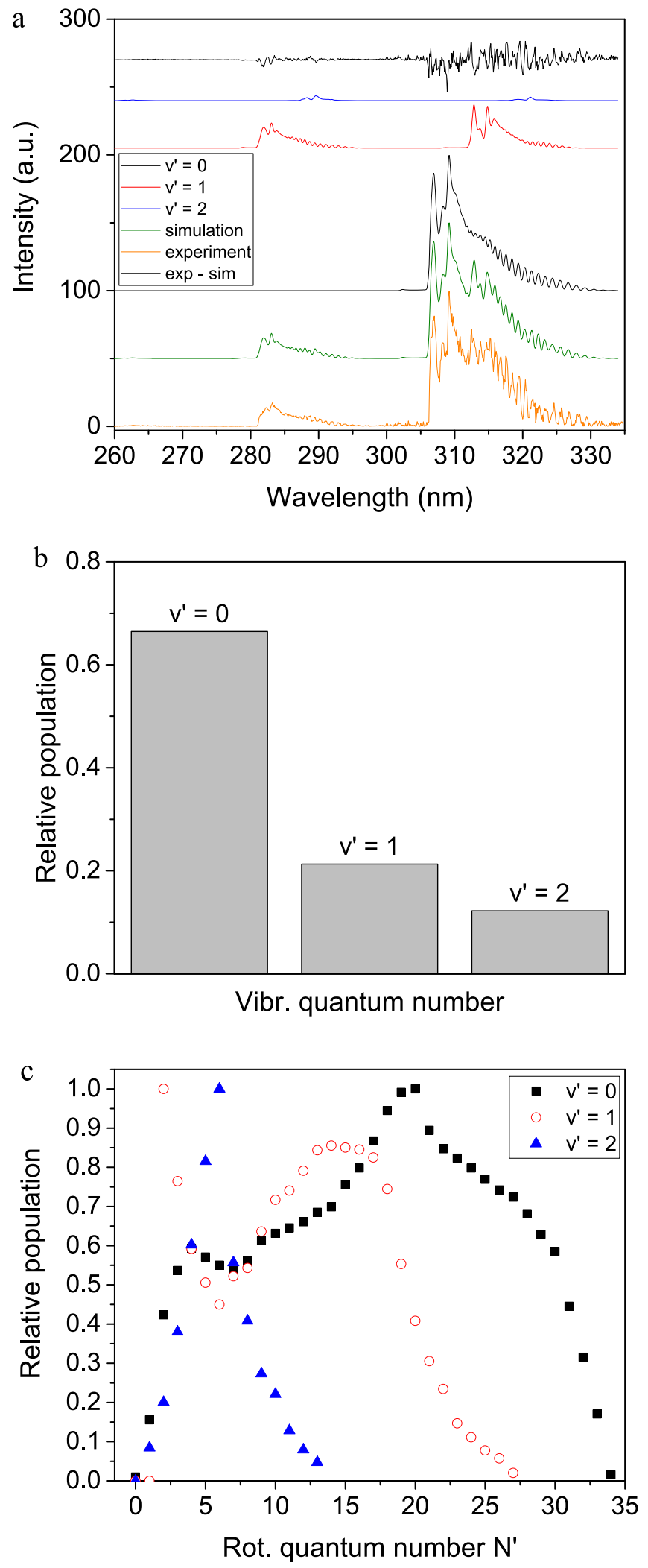

Figure 6. (a) Comparison of the synthetic $\mathrm{OH}\left(\mathrm{A}^{2} \Sigma^{+}-\mathrm{X}{ }^{2} \Pi\right)$ spectrum (green) with the experimental spectrum (orange). Individual components of the synthetic spectrum for $v^{\prime}=0$ (top black), $v^{\prime}=1$ (red) and $n^{\prime}=2$ (blue), as well as the difference between the synthetic and experimental spectrum (center; black) are also shown. (b) Relative population of vibrational states of $\mathrm{OH}$ (A ${ }^{2} \Sigma^{+}$) by electron impact on $\mathrm{H}_{2} \mathrm{O}$ according to the simulation fitted to the measured spectrum. (c) Distribution of rotational levels of the $\mathrm{OH}\left(\mathrm{A}^{2} \Sigma^{+}\right)$ state produced by electron impact on water vapor according to the simulation fitted to the measured spectrum.
Table 5

Absolute Emission Cross Sections $\sigma$ of $\mathrm{OH}\left(\mathrm{A}^{2} \Sigma^{+}-\mathrm{X}^{2} \Pi\right)$ for $50 \mathrm{eV}$ Electron Impact on Water

\begin{tabular}{ccccc}
\hline \hline$v^{\prime}-v^{\prime \prime}$ & $\begin{array}{c}\sigma \\
\left(\mathrm{cm}^{2}\right)\end{array}$ & $\begin{array}{c}\text { Unresolved } \\
(\text { model }) \\
\left(\mathrm{cm}^{2}\right)\end{array}$ & $\begin{array}{c}\text { Unresolved } \\
(\text { experiment }) \\
\text { at } 50 \mathrm{eV} \\
\left(\mathrm{cm}^{2}\right)\end{array}$ & $\begin{array}{c}\text { Müller et al. } \\
(1993) \\
(\text { unresolved }) \\
\text { at } 100 \mathrm{eV} \\
\left(\mathrm{cm}^{2}\right)\end{array}$ \\
\hline$(0-0)$ & $1.14 \times 10^{-18}$ & $1.38 \times 10^{-18}$ & $1.39 \times 10^{-18}$ & $2.68 \times 10^{-18}$ \\
\hline$(1-1)$ & $2.30 \times 10^{-19}$ & & & \\
\hline$(2-2)$ & $8.56 \times 10^{-21}$ & & & \\
\hline$(1-0)$ & $1.39 \times 10^{-19}$ & $1.52 \times 10^{-19}$ & $1.56 \times 10^{-19}$ & $3.4 \times 10^{-19}$ \\
\hline$(2-1)$ & $1.34 \times 10^{-20}$ & & & $\ldots$ \\
\hline$(2-0)$ & $1.83 \times 10^{-21}$ & $\ldots$ & $4.64 \times 10^{-21}$ & $\ldots$ \\
\hline
\end{tabular}

Note. "Unresolved" implies the total emission cross sections of bands within the emission features at 307-330 nm (top three rows) and 280-295 nm (next two rows). The uncertainties of the shown values are approximately $20 \%$ (see Section 2.4 for details).

Table 6

Absolute Emission Cross Sections $\sigma$ in $\mathrm{cm}^{2}$ of $\mathrm{OH}^{+}\left(\mathrm{A}^{3} \Pi-\mathrm{X}^{3} \Sigma^{-}\right)$and $\mathrm{H}_{2} \mathrm{O}^{+}\left(\mathrm{A}^{2} \mathrm{~A}_{1}-\mathrm{X}^{2} \mathrm{~B}_{1}\right)$ for Electron Impact on Water at Incident Energies of $50 \mathrm{eV}$

\begin{tabular}{lcc}
\hline \hline Transition & $\begin{array}{c}\text { Integration Boundaries } \\
(\mathrm{nm})\end{array}$ & $\begin{array}{c}\text { Experimental } \sigma \\
\left(\mathrm{cm}^{2}\right)\end{array}$ \\
\hline $\mathrm{OH}^{+}(\mathrm{A}-\mathrm{X})(0-0)$ & $356.7-367.0$ & $2.04 \times 10^{-20}$ \\
$\mathrm{OH}^{+}(\mathrm{A}-\mathrm{X})(1-0)$ & $333.3-340.8$ & $1.41 \times 10^{-20}$ \\
$\mathrm{OH}^{+}(\mathrm{A}-\mathrm{X})(1-1)$ & $367.2-378.0$ & $1.20 \times 10^{-20}$ \\
$\mathrm{OH}^{+}(\mathrm{A}-\mathrm{X})(2-1)$ & $346.6-356.0$ & $1.75 \times 10^{-20}$ \\
$\mathrm{H}_{2} \mathrm{O}^{+}(\mathrm{A}-\mathrm{X})(0,12,0)-(0,0,0)$ & $495.8-496.6$ & $2.76 \times 10^{-20}$ \\
$\mathrm{H}_{2} \mathrm{O}^{+}(\mathrm{A}-\mathrm{X})(0,13,0)-(0,1,0)$ & $502.8-503.8$ & $2.63 \times 10^{-20}$ \\
$\mathrm{H}_{2} \mathrm{O}^{+}(\mathrm{A}-\mathrm{X})(0,11,0)-(0,0,0)$ & $519.3-520.3$ & $2.46 \times 10^{-20}$ \\
\hline
\end{tabular}

Note. Due to weak intensities and band overlaps we estimate the uncertainty of the shown values to be approximately $30 \%$.

(Feldman et al. 2004). In comet atmospheres, those are mainly resonant fluorescent excitation (Swings 1941; Schleicher \& A'Hearn 1988) and emissive photodissociation ("prompt" emission; Bertaux 1986; Budzien \& Feldman 1991; A'Hearn et al. 2015; La Forgia et al. 2017). In this section, we will briefly highlight how the emission from electron impact on water vapor in near-UV optical wavelengths differs from the emission from these two other processes. We will only compare the spectral signatures; it is of note that in comet atmospheres the morphology of emission due to direct excitation mechanisms (i.e., emissive photodissociation and dissociative electron impact emission) maps the distribution of parent species $\left(\mathrm{H}_{2} \mathrm{O}\right.$ here) and can be found closer to the nucleus, whereas fluorescent emission maps the fragment species, resulting in a flatter, more extended distribution (see Bertaux 1986; Combi et al. 2004; Bodewits et al. 2016). We also note that electron impact UV emission has been evaluated in several protoplanetary disks (France et al. 2011); improved cross sections for further molecular species may allow remote characterizations of plasma environments that are beyond the reach of current spacecraft capabilities.

First, we compare fluorescent excitation and dissociative electron impact excitation of the hydrogen Balmer series. 


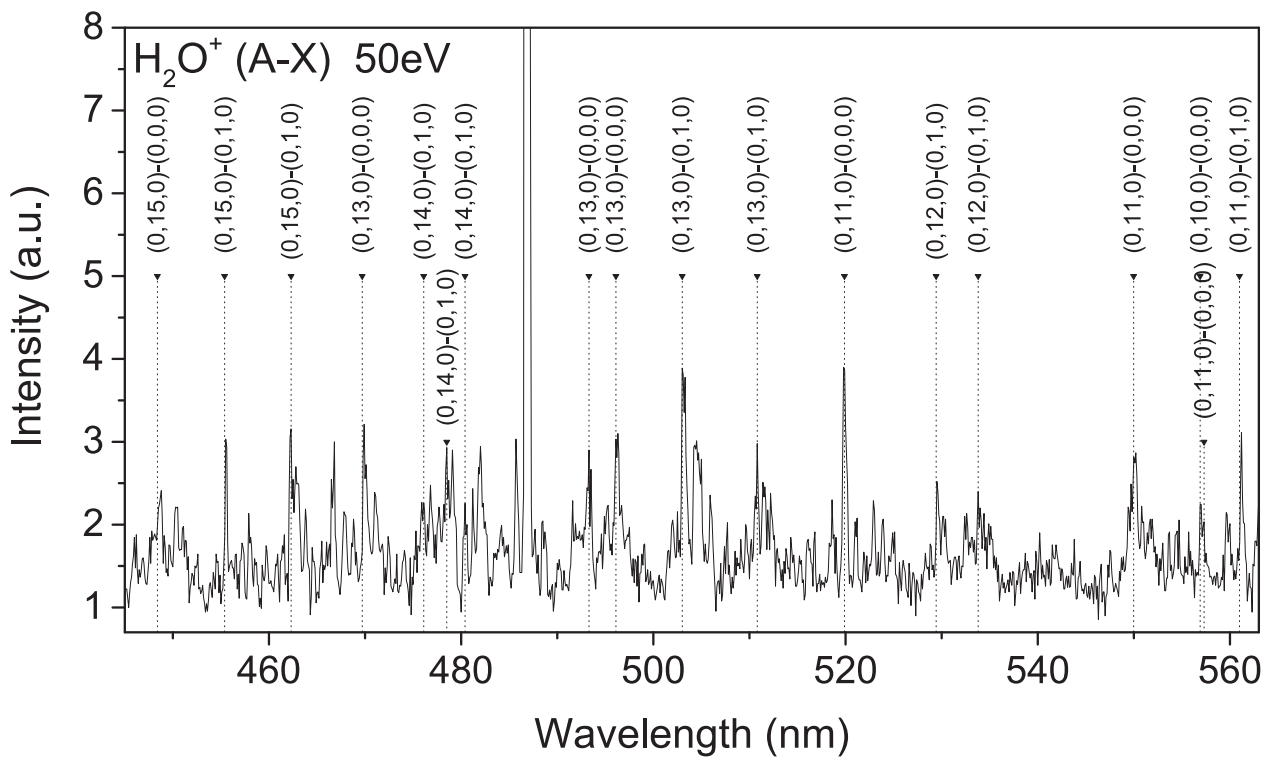

Figure 7. Higher-resolution spectrum of various vibrational transitions of $\mathrm{H}_{2} \mathrm{O}^{+}\left(\mathrm{A}^{2} \mathrm{~A}_{1}-\mathrm{X}^{2} \mathrm{~B}_{1}\right)$ measured at an electron impact energy of $50 \mathrm{eV}$.

While $\mathrm{H}_{\alpha}$ has been observed in some comets (e.g., Combi et al. 1999; Shih et al. 1984; Cochran \& Cochran 2002), the observations are challenging owing to the low surface brightness of fluorescence emission from the million-kilometer-sized hydrogen envelope of comets, and because it can be easily overwhelmed by geocoronal emission. Based on the results of the Rosetta mission (Bodewits et al. 2016), we expect electron impact emission to dominate in the inner coma $(\sim 100 \mathrm{~km})$ of comets with low production levels $\left(\sim 10^{27}\right.$ molecules $\left.\mathrm{s}^{-1}\right)$.

We estimated excitation rates of atomic hydrogen (see Feldman et al. 2004) exposed to sunlight using oscillator strengths from Wiese \& Fuhr (2009). For the solar irradiance of the Lyman lines we used the high-resolution solar spectrum acquired by the Extreme Ultraviolet Monitor on board the Maven spacecraft (Eparvier et al. 2014) during the solar maximum in 2014 and we assumed a heliocentric distance of $1 \mathrm{au}$ and a heliocentric velocity of $0 \mathrm{~km} \mathrm{~s}^{-1}$. To determine the line strength of the Balmer series, one needs to consider the cascade population of states below those initially populated. However, because the excitation of states with $n>4$ is very small compared to $n=3,4$ (factor 20 smaller), and because we only excite states with angular momentum $l=1$ we can ignore cascade population here. This implies that for the fluorescence emission, the line strength is given by the excitation rate weighed by the transitions branching ratios, which are 0.88 for the Lyman series and 0.12 for the Balmer series (Omidvar 1980). The resulting relative line strengths are given in Table 7. The ratio between the $\mathrm{H}_{\alpha}$ and $\mathrm{H}_{\beta}$ is similar for electron impact (above energies of $40 \mathrm{eV}$ ) and resonant fluorescence, but electron impact results in more higher-order $(n>4)$ Balmer lines. In the case of electron impact, these ratios do vary with energy (Figure 3(b)); they increase steeply at energies exceeding the onset of the channels and reach a maximum at electron impact energies of approximately $40 \mathrm{eV}$, after which they decrease slightly again. This implies that the ratio between the $\mathrm{H}_{\alpha}, \mathrm{H}_{\beta}$, and $\mathrm{H}_{\gamma}$ can be used as a remote diagnostic of the electron temperature.

Second, we consider the spectrum of $\mathrm{OH}\left(\mathrm{A}^{2} \Sigma^{+}-\mathrm{X}^{2} \Pi\right)$. As is shown in Figure 9, the three different excitation processes lead to distinctly different emission spectra between 260 and
$335 \mathrm{~nm}$. Emissive photodissociation by Ly $\alpha$ emission is known to produce $\mathrm{OH}\left(\mathrm{A}^{2} \Sigma^{+}\right)$with relative populations in the $v=0$, 1 , and 2 of 1:0.3 $\leqslant 0.01$ (Carrington 1964; Harich et al. 2000; A'Hearn et al. 2015). It also leads to the population of high rotational states, which have typical quantum numbers $17 \leqslant N$ $(v=0) \leqslant 22$ and $12 \leqslant N(v=1) \leqslant 17$ for the two vibrational levels. The population of vibrational levels by fluorescent excitation will depend heavily on the heliocentric velocity of a comet through the Swings effect, but generally leads to the population of much lower rotational states $(N \leqslant 5$; Schleicher \& A'Hearn 1988; La Forgia et al. 2017). Finally, dissociative electron impact leads to a relatively large population of the $v=2$ level (1:0.3:0.2) for $v=0,1$, and 2, respectively, and to a superposition of two clearly non-thermal distributions of the rotational states (Figure 6). The resulting $\mathrm{OH}\left(A^{2} \Sigma^{+}-\mathrm{X}^{2} \Pi\right)$ spectra produced by fluorescence excitation, emissive photodissociation, and electron impact dissociation excitation are markedly different (Figure 9). In the fluorescence spectrum, the emission peaks between 305 and $310 \mathrm{~nm}$ (Schleicher \& A'Hearn 1988). Emissive photodissociation results in a spectrum with much stronger emission between 280 and $290 \mathrm{~nm}$, additional emission at $307 \mathrm{~nm}$, and two broad maxima in the region between 305 and $310 \mathrm{~nm}$ and $312-318 \mathrm{~nm}(\mathrm{La}$ Forgia et al. 2017). Electron-impact dissociation results in a more continuous spectrum with maxima at $305,309,312$, and $315 \mathrm{~nm}$.

Third, the emission features discussed here all correspond to different reaction channels, each with its own threshold (Tables 3 and 4). In astrophysical environments electrons will not be mono-energetic like those in our setup (see Broiles et al. 2016), and the onset and disappearance of emission features is tied to the temperature of the incidence electrons. For example, the $\mathrm{OH}\left(\mathrm{A}^{2} \Sigma^{+}-\mathrm{X}^{2} \Pi\right)$ band occurs around $9.2 \mathrm{eV}$, or about $100,000 \mathrm{~K} ; \mathrm{H} \alpha$ appears at $17.7 \mathrm{eV}$, or $200,000 \mathrm{~K}$. Optical and near-UV emission features of electron impact dissociation can thus be used as a remote plasma diagnostic.

Fourth, the electron impact-induced spectra can be used as templates to identify emission lines in astrophysical spectra. For example, while analyzing our results, we compared the $\mathrm{H}_{2} \mathrm{O}^{+}\left(\mathrm{A}^{2} \mathrm{~A}_{1}-\mathrm{X}^{2} \mathrm{~B}_{1}\right)$ spectra from our experiments and those 

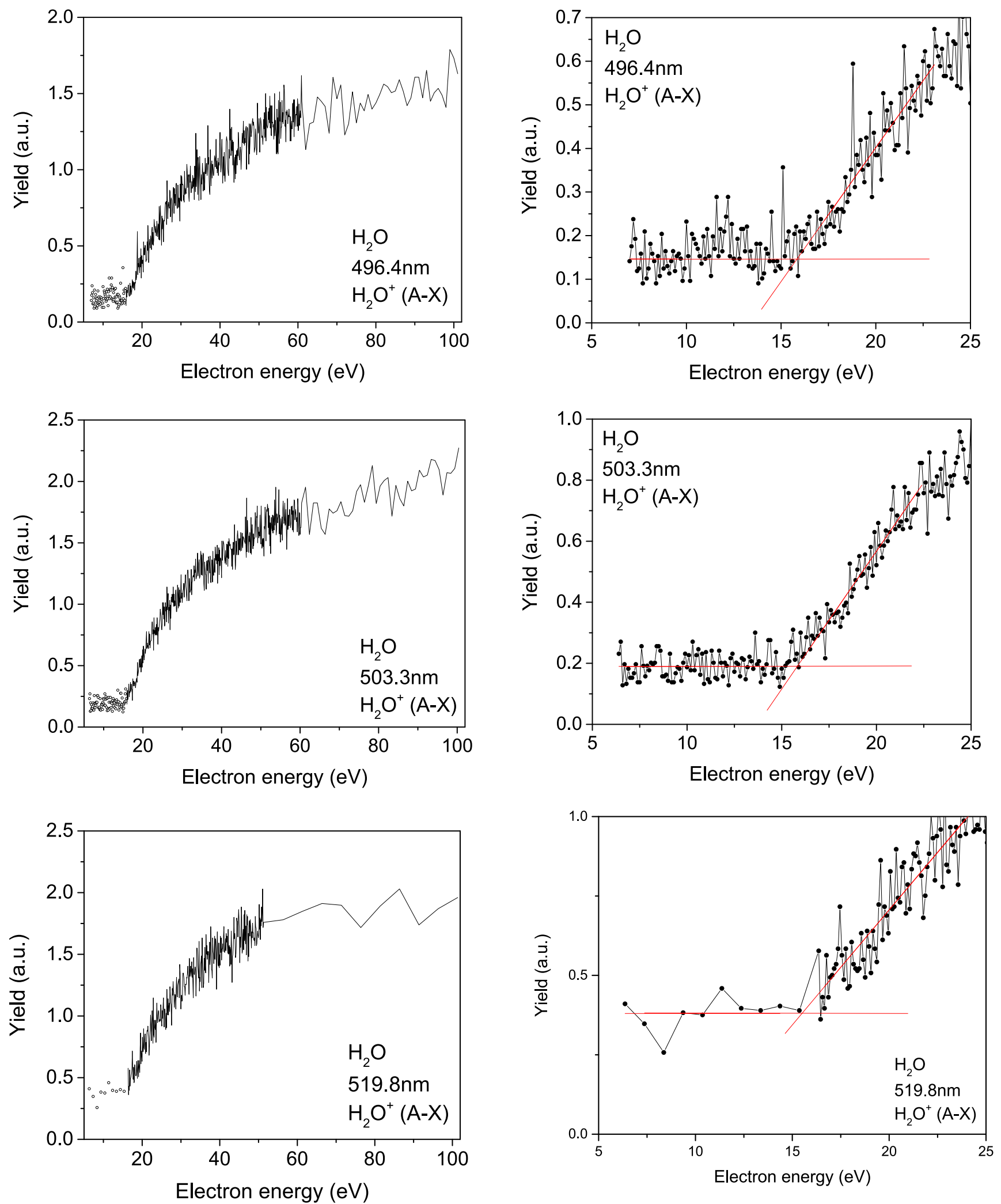

Figure 8. Electron-impact energy dependence of emission cross sections of different emission features that are part of the $\mathrm{H}_{2} \mathrm{O}^{+}\left(\mathrm{A}^{2} \mathrm{~A}_{1}-\mathrm{X}^{2} \mathrm{~B}_{1}\right)$ band, measured at $496.4 \mathrm{~nm}$ (top left), $503.3 \mathrm{~nm}$ (top right), and $519.8 \mathrm{~nm}$ (bottom). Threshold fits are shown in the right column.

by Kuchenev \& Smirnov (1996) with observations of comet ion tails (Wyckoff et al. 1999; Kawakita \& Watanabe 2002) and found that many unidentified lines could be attributed to transitions from the higher vibrational levels of the
$\mathrm{H}_{2} \mathrm{O}^{+}\left(\mathrm{A}^{2} \mathrm{~A}_{1}-\mathrm{X}^{2} \mathrm{~B}_{1}\right)$ band, levels which were not considered in fluorescence models.

To facilitate the application of our results in astrophysical models, we provide polynomial fits to the data in the Appendix. 


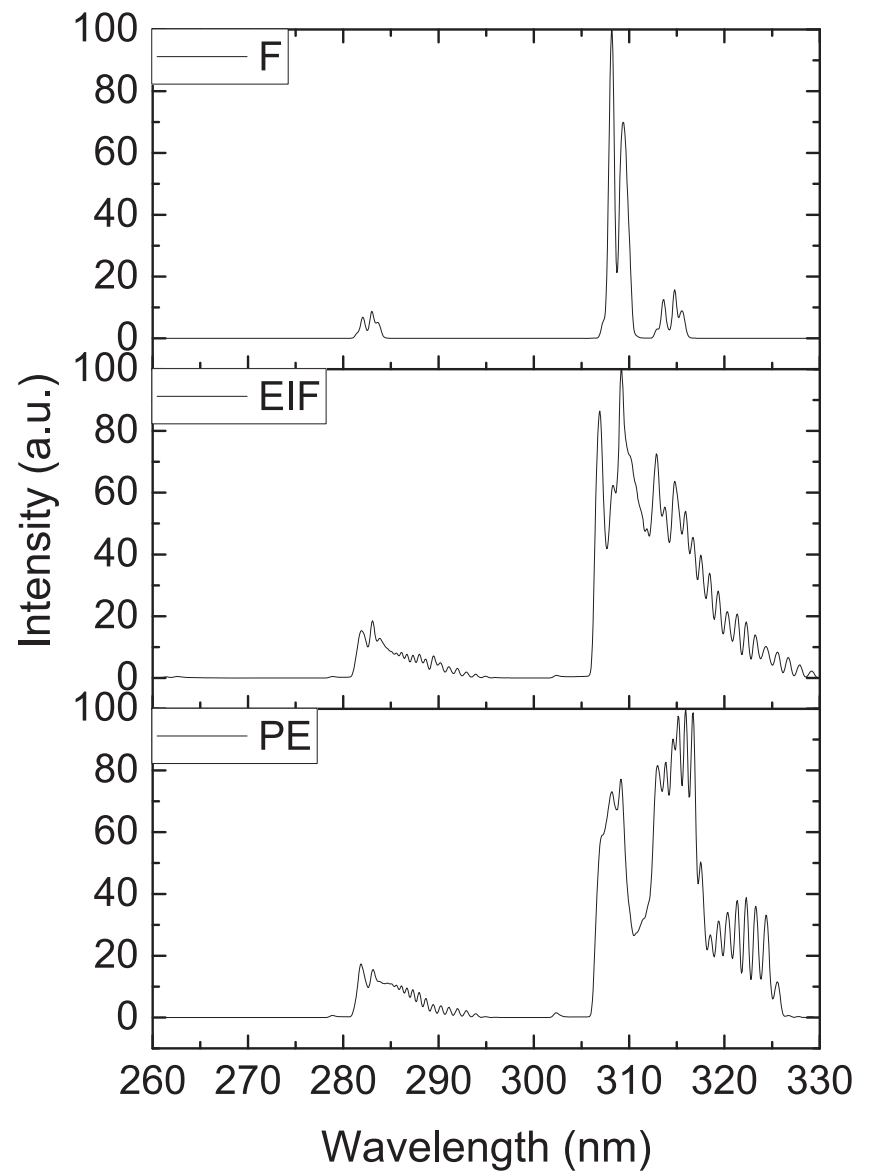

Figure 9. Comparison of simulated $\mathrm{OH}\left(\mathrm{A}^{2} \Sigma^{+}-\mathrm{X}^{2} \Pi\right)$ spectra caused by different processes. Top: fluorescence excitation of $\mathrm{OH}$ at a heliocentric velocity of $2.13 \mathrm{~km} \mathrm{~s}^{-1}$ (based on a level distribution from D. Schleicher 2019, private communication). Center: electron impact of $\mathrm{H}_{2} \mathrm{O}$ at an incident energy of $50 \mathrm{eV}$ (this paper). Bottom: emissive photodissociation of $\mathrm{H}_{2} \mathrm{O}$ (La Forgia et al. 2017). The spectral resolution for these simulations is $0.5 \mathrm{~nm}$.

Table 7

Relative Line Strengths of the Hydrogen Balmer Series with Respect to $\mathrm{H}_{\alpha}$ for Electron Impact on Water Vapor at Energies of 50 and $100 \mathrm{eV}$ (see Table 2), Compared to Resonant Fluorescence by Hydrogen Atoms

\begin{tabular}{lccc}
\hline \hline Transition & \multicolumn{3}{c}{ Relative Strength Compared to $\mathrm{H}_{\alpha}$} \\
\cline { 2 - 4 } & $\begin{array}{c}\text { Electron Impact } \\
\text { at } 50 \mathrm{eV}\end{array}$ & $\begin{array}{c}\text { Electron Impact at } \\
100 \mathrm{eV}\end{array}$ & Fluorescence \\
\hline $\mathrm{H}_{\alpha}(3-2)$ & 1.00 & 1.00 & 1.00 \\
$\mathrm{H}_{\beta}(4-2)$ & 0.23 & 0.19 & 0.23 \\
$\mathrm{H}_{\gamma}(5-2)$ & 0.13 & 0.09 & 0.01 \\
$\mathrm{H}_{\delta}(6-2)$ & 0.05 & 0.04 & 0.02 \\
$\mathrm{H}_{\varepsilon}(7-2)$ & 0.04 & 0.03 & 0.01 \\
\hline
\end{tabular}

\section{Conclusions}

Electron-impact reactions can be used to remotely detect and characterize volatiles in the solar system. To discover and interpret this emission, a thorough understanding of dissociative electron impact reactions is required. Water is ubiquitous in the solar system and one of the main constituents of the tenuous atmospheres of small bodies such as comets. We have experimentally studied the dissociative excitation of water molecules using a crossed-beam setup equipped with multiple electron sources and spectrometers. This allowed us to characterize the emission cross sections of excited $\mathrm{OH}$, atomic hydrogen, and the ions $\mathrm{H}_{2} \mathrm{O}^{+}$and $\mathrm{OH}^{+}$, as well as the impact energies above which those excited products were formed. The first emission features to appear are the $\mathrm{OH}\left(\mathrm{A}^{2} \Sigma^{+}-\mathrm{X}^{2} \Pi\right)$ bands between 260 and $335 \mathrm{~nm}$, with a threshold of $9.4 \pm$ $0.3 \mathrm{eV}$. The $\mathrm{OH}^{+}\left(\mathrm{A}^{3} \Pi-\mathrm{X}^{3} \Sigma^{-}\right)$and $\mathrm{H}_{2} \mathrm{O}^{+}\left(\mathrm{A}^{2} \mathrm{~A}_{1}-\mathrm{X}^{2} \mathrm{~B}_{1}\right)$ features occur next at incident energies above $13 \pm 0.3$ and $15.8 \pm 0.3 \mathrm{eV}$, respectively. Finally, above $17.7 \pm 0.3 \mathrm{eV}$, the hydrogen Balmer series was detected. These values are in good agreement with thermochemical estimates and previous experiments.

We have investigated the brightest features, the $\mathrm{OH}\left(\mathrm{A}^{2} \Sigma^{+}-\right.$ $\left.\mathrm{X}^{2} \Pi\right)$ and the hydrogen Balmer series in the most detail, comparing our results to previously published studies. Theoretical simulations of the $\mathrm{OH}\left(\mathrm{A}^{2} \Sigma^{+}-\mathrm{X}^{2} \Pi\right)$ bands were used to determine emission cross sections of individual vibrational transitions that are not distinguishable in experimental spectrum. To aid the diagnostic application of our experimental results, we produced empirical fits to the electron impact-dependent emission cross sections.

Following the findings of the Rosetta mission to comet 67P/ Churyumov-Gerasimenko that electron impact reactions might rival photolysis and fluorescence in certain circumstances, we explored the diagnostic application of electron impact excitation in cometary atmospheres. For hydroxyl, electron impact dissociation leads to a rovibrational excitation that is distinctly different than that produced by resonant photofluorescence and emissive photodissociation. This phenomenon can be used for remote determination of the primary process leading to excitation. While our experiment cannot be used to reconstruct the detailed distribution over the quantum and angular momentum states of the excited hydrogen, the relative intensities of the hydrogen Balmer series are very different when produced by electron impact reactions with $\mathrm{H}_{2} \mathrm{O}$ rather than through the photofluorescence of atomic hydrogen. In short, given the proper signal-to-noise ratio, spectral observations of interactions between neutral molecules and energetic plasmas, like those within cometary comae, can isolate portions of the tenuous gas dominated by electron impactor photofluoresence based on the relative intensities of the Balmer series.

While water is the main volatile in comets, their comae contain many other molecules such as $\mathrm{CO}_{2}, \mathrm{CO}, \mathrm{HCN}, \mathrm{NH}$, and $\mathrm{O}_{2}$, species that are also present in the atmospheres of other small bodies in the solar system. We hope to explore the electron-induced dissociative excitation of these molecules and their fragments and ions in future studies.

We thank Dr. D. Schleicher (Lowell Observatory) for sharing the results of his $\mathrm{OH}$ fluorescence calculations, and Dr. H. Kawakita for discussing the line identification of $\mathrm{H}_{2} \mathrm{O}^{+}$in comet tails. Support for Program number HST-GO15625.001 (D.B., J.N.) was provided by NASA through a grant from the Space Telescope Science Institute, which is operated by the Association of Universities for Research in Astronomy, Incorporated, under NASA contract NAS5-26555. This project has received funding from the European Union's Horizon 2020 research and innovation programme under grant agreement No 692335. This work was supported by the Slovak Research and Development Agency APVV-15-0580 and the Slovak Grant Agency for Science (contract no. VEGA 1/0733/17). 


\section{Appendix}

These polynomials are purely mathematical fits with no theoretical basis. The determined cross-section curves (both absolutely calibrated and relative ones) were smoothed and fitted by polynomial functions of the ninth order valid in the range from the threshold of the process up to $100 \mathrm{eV}$ (see Tables 8, 9, and 10). In specific cases $\left(\mathrm{H}_{\beta}\right.$ and $\left.\mathrm{H}_{\gamma}\right)$ it was necessary to divide the range into two parts and fit them separately, as using only one function for the whole range would lead to discrepancies between fit and real values around the second threshold.

Table 8

Parameters of the Polynomial Fits of the Determined Excitation-emission Cross-section Curves

\begin{tabular}{|c|c|c|c|c|}
\hline & $\begin{array}{l}\mathrm{H}(3-2) \\
\text { Range: }\end{array}$ & $\begin{array}{l}\mathrm{H}(4-2) \\
\text { Range: }\end{array}$ & Range: & $\begin{array}{l}\mathrm{H}(5-2) \\
\text { Range: }\end{array}$ \\
\hline & $17.74-100 \mathrm{eV}$ & $18.46-25 \mathrm{eV}$ & $25-100 \mathrm{eV}$ & $18.6-100 \mathrm{eV}$ \\
\hline$A_{0}$ & $1.166448197771539 \mathrm{e}-21$ & 7.639860613710967e-16 & $4.943728915208466 \mathrm{e}-17$ & $-1.3340396166601772 \mathrm{e}-18$ \\
\hline $\mathrm{A}_{1}$ & $9.303043241829306 \mathrm{e}-20$ & $-4.339906653651744 \mathrm{e}-16$ & $-8.284530518495484 \mathrm{e}-18$ & $3.142413051829726 \mathrm{e}-19$ \\
\hline $\mathrm{A}_{2}$ & $-1.047964582351875 \mathrm{e}-20$ & $1.0844583626545231 \mathrm{e}-16$ & $5.932055298901659 \mathrm{e}-19$ & $-3.087841795930737 \mathrm{e}-20$ \\
\hline $\mathrm{A}_{3}$ & $2.828752787633401 \mathrm{e}-22$ & $-1.5639628844033396 \mathrm{e}-17$ & $-2.390354805210368 \mathrm{e}-20$ & $1.6552067983794612 \mathrm{e}-21$ \\
\hline $\mathrm{A}_{4}$ & $1.608911911675589 \mathrm{e}-23$ & $1.4341280890695941 \mathrm{e}-18$ & $6.003860671654366 \mathrm{e}-22$ & $-5.323693565345372 \mathrm{e}-23$ \\
\hline $\mathrm{A}_{5}$ & $-1.087476686916897 \mathrm{e}-24$ & $-8.669350340974055 \mathrm{e}-20$ & $-9.783989360655368 \mathrm{e}-24$ & $1.0748791030573578 \mathrm{e}-24$ \\
\hline $\mathrm{A}_{6}$ & $2.6022714570262697 \mathrm{e}-26$ & $3.454204282746568 \mathrm{e}-21$ & $1.0379278535794464 \mathrm{e}-25$ & $-1.3740836557017882 \mathrm{e}-26$ \\
\hline$A_{7}$ & $-3.120952424581023 \mathrm{e}-28$ & $-8.746607094179829 \mathrm{e}-23$ & $-6.931564067835833 \mathrm{e}-28$ & $1.0801017593637847 \mathrm{e}-28$ \\
\hline$A_{8}$ & $1.8805374063667342 \mathrm{e}-30$ & $1.2772175870694166 \mathrm{e}-24$ & $2.6503850787057475 \mathrm{e}-30$ & $-4.76448663594286 \mathrm{e}-31$ \\
\hline $\mathrm{A}_{9}$ & $-4.5367494258922786 \mathrm{e}-33$ & $-8.195318726717443 \mathrm{e}-27$ & $-4.4286991283227496 \mathrm{e}-33$ & $9.028240042967173 \mathrm{e}-34$ \\
\hline
\end{tabular}

Note. The curves were fitted by the polynomial function $y=A_{0}+A_{1} \cdot x+A_{2} \cdot x^{2}+\ldots+A_{9} \cdot x^{9}$. The fits are valid only in the electron-energy range given.

Table 9

Parameters of the Polynomial Fits of the Determined Excitation-emission Cross-section Curves

\begin{tabular}{ccccc}
\hline \hline $\mathrm{H}(6-2)$ & & $\mathrm{H}(7-2)$ & $\mathrm{OH}(\mathrm{A}-\mathrm{X})(0-0)$ & $\mathrm{OH}(\mathrm{A}-\mathrm{X})(1-0)$ \\
\hline Range: & Range: & Range: & Range: & Range: \\
$19.45-25 \mathrm{eV}$ & $25-100 \mathrm{eV}$ & $20-100 \mathrm{eV}$ & $9.3-100 \mathrm{eV}$ & $9.4-100 \mathrm{eV}$ \\
\hline
\end{tabular}

\begin{tabular}{lccccc}
\hline $\mathrm{A}_{0}$ & $4.6050832232610517 \mathrm{e}-20$ & $2.7887405837723353 \mathrm{e}-18$ & $2.5224214271660094 \mathrm{e}-22$ & $-1.6708105463999309 \mathrm{e}-18$ & $-1.6068108298970508 \mathrm{e}-18$ \\
\hline $\mathrm{A}_{1}$ & $-9.374373347463644 \mathrm{e}-21$ & $-4.625627979181022 \mathrm{e}-19$ & $-9.344411261004822 \mathrm{e}-22$ & $-5.003481239748052 \mathrm{e}-19$ & $3.591444305340944 \mathrm{e}-19$ \\
\hline $\mathrm{A}_{2}$ & $-4.7778670332226695 \mathrm{e}-21$ & $3.290421775742448 \mathrm{e}-20$ & $2.0011358601925912 \mathrm{e}-22$ & $1.501604107447954 \mathrm{e}-19$ & $-3.02044645641766 \mathrm{e}-20$ \\
\hline $\mathrm{A}_{3}$ & $2.3619183204472313 \mathrm{e}-21$ & $-1.3201234056221827 \mathrm{e}-21$ & $-1.6159383332511198 \mathrm{e}-23$ & $-1.1353168952795955 \mathrm{e}-20$ & $1.4454391127131222 \mathrm{e}-21$ \\
\hline $\mathrm{A}_{4}$ & $-4.447622886730001 \mathrm{e}-22$ & $3.3050664777090135 \mathrm{e}-23$ & $7.094824362753076 \mathrm{e}-25$ & $4.265395602292418 \mathrm{e}-22$ & $-4.3647020503110567 \mathrm{e}-23$ \\
\hline $\mathrm{A}_{5}$ & $4.610214959628704 \mathrm{e}-23$ & $-5.369524359823974 \mathrm{e}-25$ & $-1.8453223153121365 \mathrm{e}-26$ & $-9.315104529482383 \mathrm{e}-24$ & $8.588802513522081 \mathrm{e}-25$ \\
\hline $\mathrm{A}_{6}$ & $-2.8512295407360197 \mathrm{e}-24$ & $5.673896248847104 \mathrm{e}-27$ & $2.9162264157020105 \mathrm{e}-28$ & $1.2388681669547896 \mathrm{e}-25$ & $-1.0970024924927756 \mathrm{e}-26$ \\
\hline $\mathrm{A}_{7}$ & $1.0487461432786806 \mathrm{e}-25$ & $-3.7674680609698995 \mathrm{e}-29$ & $-2.7467021627222484 \mathrm{e}-30$ & $-9.900092258118275 \mathrm{e}-28$ & $8.753050817957322 \mathrm{e}-29$ \\
\hline $\mathrm{A}_{8}$ & $-2.1181961623891444 \mathrm{e}-27$ & $1.4285969698096938 \mathrm{e}-31$ & $1.416522775284146 \mathrm{e}-32$ & $4.3712669183598735 \mathrm{e}-30$ & $-3.957593265862472 \mathrm{e}-31$ \\
\hline $\mathrm{A}_{9}$ & $1.8088489514284093 \mathrm{e}-29$ & $-2.359940585253714 \mathrm{e}-34$ & $-3.0761767267104824 \mathrm{e}-35$ & $-8.196452209932972 \mathrm{e}-33$ & $7.729341580431711 \mathrm{e}-34$
\end{tabular}

Note. The curves were fitted by the polynomial function $y=A_{0}+A_{1} \cdot x+A_{2} \cdot x^{2}+\ldots+A_{9} \cdot x^{9}$. The fits are valid only in the electron-energy range given. 
Table 10

Parameters of the Polynomial Fits of the Determined Relative Excitation-emission Curves

\begin{tabular}{lcccc}
\hline & $\mathrm{OH}^{+}(\mathrm{A}-\mathrm{X})(0-0)$ & $\mathrm{H}_{2} \mathrm{O}^{+}(\mathrm{A}-\mathrm{X}) 496.4 \mathrm{~nm}$ & $\mathrm{H}_{2} \mathrm{O}^{+}(\mathrm{A}-\mathrm{X}) 503.3 \mathrm{~nm}$ & $\mathrm{H} \mathrm{O}^{+}(\mathrm{A}-\mathrm{X}) 519.8 \mathrm{~nm}$ \\
\hline $\begin{array}{c}\text { Range: } \\
23-100 \mathrm{eV}\end{array}$ & $\begin{array}{c}\text { Range: } \\
15.8-100 \mathrm{eV}\end{array}$ & $\begin{array}{c}\text { Range: } \\
15.8-100 \mathrm{eV}\end{array}$ & $\begin{array}{c}\text { Range: } \\
15.5-100 \mathrm{eV}\end{array}$ \\
\hline $\mathrm{A}_{0}$ & $-4.879653950408096 \mathrm{e}-21$ & $8.858789956334654 \mathrm{e}-20$ & $8.393390382947733 \mathrm{e}-20$ & $-1.1149998139715028 \mathrm{e}-19$ \\
\hline $\mathrm{A}_{1}$ & $2.659247657749363 \mathrm{e}-21$ & $-1.9908158448335207 \mathrm{e}-20$ & $-2.1597167385367772 \mathrm{e}-20$ & $2.2894976608348353 \mathrm{e}-20$ \\
\hline $\mathrm{A}_{2}$ & $-1.7627911756207753 \mathrm{e}-22$ & $1.7733554480488418 \mathrm{e}-21$ & $2.1710745284722074 \mathrm{e}-21$ & $-2.0344880667853087 \mathrm{e}-21$ \\
\hline $\mathrm{A}_{3}$ & $-1.6520163112711283 \mathrm{e}-24$ & $-8.131201536101095 \mathrm{e}-23$ & $-1.1261321281605362 \mathrm{e}-22$ & $1.0594033792359092 \mathrm{e}-22$ \\
\hline $\mathrm{A}_{4}$ & $6.342836468753547 \mathrm{e}-25$ & $2.172870150769907 \mathrm{e}-24$ & $3.4685543164993574 \mathrm{e}-24$ & $-3.436446082576604 \mathrm{e}-24$ \\
\hline $\mathrm{A}_{5}$ & $-2.769228380473545 \mathrm{e}-26$ & $-3.5155158139396874 \mathrm{e}-26$ & $-6.674381095138968 \mathrm{e}-26$ & $7.137233719051186 \mathrm{e}-26$ \\
\hline $\mathrm{A}_{6}$ & $5.696303051428173 \mathrm{e}-28$ & $3.403293871656412 \mathrm{e}-28$ & $8.089104069469202 \mathrm{e}-28$ & $-9.480450797570219 \mathrm{e}-28$ \\
\hline $\mathrm{A}_{7}$ & $-6.2909781392886665 \mathrm{e}-30$ & $-1.8341384208676137 \mathrm{e}-30$ & $-5.9900506073436436 \mathrm{e}-30$ & $7.778923273105029 \mathrm{e}-30$ \\
\hline $\mathrm{A}_{8}$ & $3.6037202657997516 \mathrm{e}-32$ & $4.456416074602091 \mathrm{e}-33$ & $2.471321253124862 \mathrm{e}-32$ & $-3.5874248127206663 \mathrm{e}-32$ \\
\hline $\mathrm{A}_{9}$ & $-8.423875581896907 \mathrm{e}-35$ & $-1.7179486857965017 \mathrm{e}-36$ & $-4.3454776734175923 \mathrm{e}-35$ & $7.106174063364234 \mathrm{e}-35$ \\
\hline
\end{tabular}

Note. The curves were fitted by the polynomial function $y=A_{0}+A_{1} \cdot x+A_{2} \cdot x^{2}+\ldots+A_{9} \cdot x^{9}$. The fits are valid only in the shown electron-energy range.

\section{ORCID iDs}

D. Bodewits iㅏ https://orcid.org/0000-0002-2668-7248

J. Országh @i https://orcid.org/0000-0002-4309-6060

J. Noonan $\odot$ il https://orcid.org/0000-0003-2152-6987

Š. Matejčík i https://orcid.org/0000-0001-7238-5964

\section{References}

A’Hearn, M. F., Krishna Swamy, K. S., Wellnitz, D. D., \& Meier, R. 2015, AJ, 150,5

Avakyan, S. V., Ii'ln, R. N., Lavrov, V. M., Ogurtsov, G. N., et al. 1998, in Collision Processes and Excitation of UV Emission from Planetary Atmospheric Gases: A Handbook of Cross Sections, ed. S. V. Avakyan (Amsterdam: Gordon and Breach)

Bagenal, F., Sidrow, E., Wilson, R. J., et al. 2015, Icar, 261, 1

Becker, K., Stumpf, B., Schulz, G., et al. 1980, CP, 154, 110

Beenakker, C., de Heer, F., \& Krop, H. B. 1974, CP, 6, 445

Berman, A. 1996, Vacuu, 47, 327

Bertaux, J.-L. 1986, A\&A, 160, L7

Bhardwaj, A., \& Raghuram, S. 2012, ApJ, 748, 13

Bodewits, D., Lara, L. M., A'Hearn, M. F., et al. 2016, AJ, 152, 130

Böse, N., \& Sroka, W. 1973, Z. für Naturforschung A, 28, 22

Broiles, T. W., Livadiotis, G., Burch, J. L., et al. 2016, JGRA, 121, 7407

Budzien, S. A., \& Feldman, P. D. 1991, Icar, 90, 308

Carrington, T. 1964, JChPh, 41, 7

Cochran, A. L., \& Cochran, W. D. 2002, Icar, 157, 297

Combi, M. R., Cochran, A. L., Cochran, W. D., Lambert, D. L., \& Johns-Krull, C. M. 1999, ApJ, 512, 961

Combi, M. R., Harris, W. M., \& Smyth, W. H. 2004, in Comets II, ed. H. A. Weaver, H. U. Keller, \& M. Festou (Tuscon, AZ: Univ. Arizona Press), 523

Cunningham, N. J., Spencer, J. R., Feldman, P. D., et al. 2015, Icar, 245, 178

Danko, M., Ribar, A., Ďurian, M., Országh, J., \& Matejčík, Š. 2016, PSST, 25, 065007

Eparvier, F. G., Chamberlin, P. C., Woods, T. N., \& Thiemann, E. M. B. 2014, SSRv, 195, 293

Feldman, P. D., A'Hearn, M. F., Bertaux, J.-L., et al. 2018, AJ, 155, 9

Feldman, P. D., Cochran, A. L., \& Combi, M. R. 2004, in Comets II, ed. H. A. Weaver, M. Festou, \& H. U. Keller (Tuscon, AZ: Univ. Arizona Press), 425

Feldman, P. D., A'Hearn, M. F., Bertaux, J. L., et al. 2015, A\&A, 583, A8
France, K., Yang, H., \& Linsky, J. L. 2011, ApJ, 729, 7

Galand, M., \& Chakrabarti, S. 2002, GMS, 130, 55

Hall, D. T., Strobel, D. F., Feldman, P. D., McGrath, M. A., \& Weaver, H. A. 1995, Natur, 373, 677

Harich, S. A., Hwang, D. W. H., Yang, X., et al. 2000, JChPh, 113, 22

Itikawa, Y., \& Mason, N. 2005, JPCRD, 34, 1

James, G. K., Ajello, J. M., \& Pryor, W. J. 1998, JGR, 103, 20113

Kawakita, H., \& Watanabe, J.-I. 2002, ApJL, 574, L183

Khodorkovskii, M. A., Murashov, S. V., Artamonova, T. O., et al. 2009, JPhB, 42, 215201

King, S. J., \& Price, S. D. 2008, IJMSp, 277, 84

Kouchi, N., Ito, K., Hatano, Y., Oda, N., \& Tsuboi, T. 1979, Chem. Phys., 36,239

Kuchenev, A. N., \& Smirnov, Y. M. 1996, CaJPh, 74, 267

Kurawaki, J., Ueki, K., Higo, M., \& Ogawa, T. 1983, J. Chem. Phys., 78, 3071

La Forgia, F., Bodewits, D., A'Hearn, M. F., et al. 2017, AJ, 154, 185

Luque, J., \& Crosley, D. R. 1999, SRI International Report, MP 99

Makarov, O. P., Ajello, J. M., Vattipalle, P., et al. 2004, JGRA, 109, A09303

McConkey, J. W., Malone, C. P., Johnson, P. V., et al. 2008, PhR, 466, 1

Möhlmann, G. R., \& De Heer, F. J. 1979, CP, 40, 157

Müller, U., Bubel, T., \& Schulz, G. 1993, ZPhyD, 25, 167

NIST 2015, NIST Atomic Spectra Database (ver. 5.0) (Gaithersburg, MD: National Institute of Standards and Technology), http://physics.nist. gov/asd

Noonan, J. W., Stern, S. A., Feldman, P. D., et al. 2018, AJ, 156, 16

Ogawa, T., Yonekura, N., Tsukada, M., et al. 1991, JChPh, 95, 2788

Omidvar, K. 1980, Tables of Transition Probabilities and Branching Ratios for Electric Dipole Transitions between Arbitrary Levels of Hydrogen-like Atoms. NASA Technical memorandum NASA-TM-80682

Országh, J., Danko, M., Ribar, A., \& Matejčík, Š. 2012, NIMPB, 279, 76

Országh, J., Danko, M., Čechvala, P., \& Matejčík, Š. 2017, ApJ, 841, 17

Roth, L., Saur, J., Retherford, K. D., et al. 2014, Sci, 343, 171

Ruscic, B., Wagner, A. F., Harding, L. B., et al. 2002, J. Phys. Chem. A, 106,2727

Schleicher, D. G., \& A'Hearn, M. F. 1988, ApJ, 331, 1058

Shappe, R. S., \& Urban, E. 2006, PhRvA, 73, 052702

Shih, P., Scherb, F., \& Roesler, F. L. 1984, ApJ, 279, 453

Swings, P. 1941, LicOB, 508, 131

Van de Burgt, P. J. M., Westerveld, W. B., \& Risley, J. S. 1989, JPCRD, 18,1757

Vroom, D. A., \& De Heer, F. J. 1969, JChPh, 50, 1883

Wiese, W. L., \& Fuhr, J. R. 2009, JPCRD, 38, 565, Erratum: 38, 1129 (2009)

Wyckoff, S., Heyd, R. S., \& Fox, R. 1999, ApJL, 512, L73 